PNNL-11787

UC-2030

\title{
TEMPEST Code Modifications and Testing for Erosion-Resisting Sludge Simulations
}

\author{
Y. Onishi
}

D. S. Trent

January 1998

Prepared for the

U.S. Department of Energy

under Contract DE-AC06-76RLO 1830

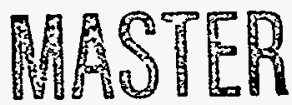

Pacific Northwest National Laboratory

Richland, Washington 99352

RISTRIBUTION OF THIS DOCURENT IS UNLIMITED 


\section{DISCLAIMER}

This report was prepared as an account of work sponsored by an agency of the United States Government. Neither the United States Government nor any agency thereof, nor any of their employees, make any warranty, express or implied, or assumes any legal liability or responsibility for the accuracy, completeness, or usefulness of any information, appa. ratus, product, or process disclosed, or represents that its use would not infringe privately owned rights. Reference herein to any specific commercial product, process, or service by trade name, trademark, manufacturer, or otherwise does not necessarily constitute or imply its endorsement, recommendation, or favoring by the United States Government or any agency thereof. The views and opinions of authors expressed herein do not necessarily state or reflect those of the United States Government or any agency thereof. 


\section{DISCLAIMER}

Portions of this document may be illegible electronic image products. Images are produced from the best available original document. 


\section{Executive Summary}

The TEMPEST computer code has been used to address many waste retrieval operational and safety questions regarding waste mobilization, mixing, and gas retention. Because the amount of sludge retrieved from the tank is directly related to the sludge yield strength and the shear stress acting upon it, it is important to incorporate the sludge yield strength into our simulations of erosion-resisting tank waste retrieval operations. This report describes current efforts to modify the TEMPEST code to simulate pump jet mixing of erosion-resisting tank wastes and the models used to test for erosion of waste sludge with yield strength. Test results for solid deposition and diluent/slurry jet injection into sludge layers in simplified tank conditions show that the modified TEMPEST code has a basic ability to simulate both the mobility and immobility of the sludges with yield strength. Further testing, modification, calibration, and verification of the sludge mobilization/immobilization model are planned using erosion data as they apply to waste $\operatorname{tank}$ sludges. 


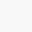




\section{Contents}

Executive Summary $\ldots \ldots \ldots \ldots \ldots \ldots \ldots \ldots \ldots \ldots \ldots \ldots \ldots \ldots \ldots \ldots$ iii

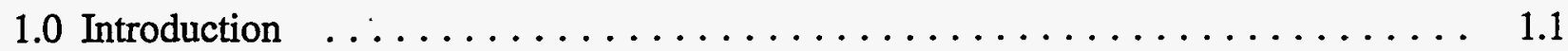

2.0 TEMPEST Description $\ldots \ldots \ldots \ldots \ldots \ldots \ldots \ldots \ldots \ldots \ldots \ldots \ldots \ldots \ldots \ldots \ldots$

2.1 Fluid Dynamics $\ldots \ldots \ldots \ldots \ldots \ldots \ldots \ldots \ldots \ldots \ldots \ldots \ldots \ldots \ldots \ldots \ldots$

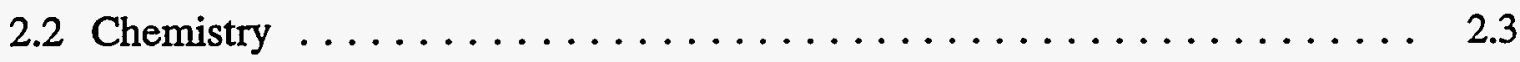

2.2.1 Equilibrium Chemical Reactions $\ldots \ldots \ldots \ldots \ldots \ldots \ldots \ldots$

2.2.2 Kinetic Chemical Reactions $\ldots \ldots \ldots \ldots \ldots \ldots \ldots \ldots$

2.3 Physical Properties and Rheology $\ldots \ldots \ldots \ldots \ldots \ldots \ldots \ldots \ldots .7$

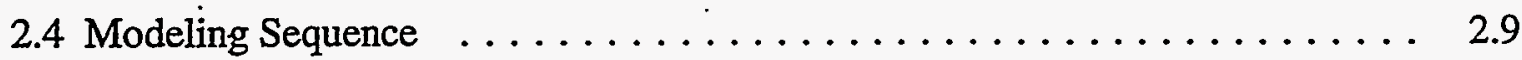

3.0 Code Modifications for Erosion of Immobile Material $\ldots \ldots \ldots \ldots \ldots \ldots \ldots . .1$

4.0 Model Testing on Solids Accumulation and Erosion $\ldots \ldots \ldots \ldots \ldots \ldots \ldots . \ldots \ldots$

4.1 Test Case 1: Solid Deposition and Accumulation in a Tank ......... 4.1

4.2 Test Case 2: Diluent Jet Injection into Tank Sludge $\ldots \ldots \ldots \ldots \ldots \ldots .9$

4.3 Test Case 3: Sludge Pump Jet Mixing $\ldots \ldots \ldots \ldots \ldots \ldots \ldots \ldots .17$

5.0 Summary and Conclusions $\ldots \ldots \ldots \ldots \ldots \ldots \ldots \ldots \ldots \ldots \ldots \ldots \ldots \ldots \ldots$

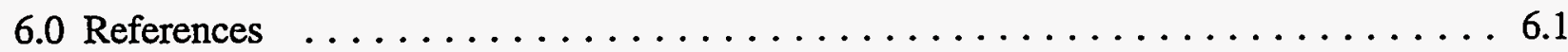




\section{Figures}

$1.1 \quad$ Sludge Pump Jet Mixing $\ldots \ldots \ldots \ldots \ldots \ldots \ldots \ldots \ldots \ldots \ldots \ldots \ldots \ldots \ldots$

1.2 Sludge Erosion Versus Shear Stress $\ldots \ldots \ldots \ldots \ldots \ldots \ldots \ldots \ldots . \ldots \ldots$

4.1 Injection and Withdrawal Nozzle Setup in a $19 \times 19 \times 19-\mathrm{ft}$ Tank $\ldots \ldots \ldots \ldots .2$

4.2 Predicted Flow and Sludge Accumulation along Tank Center at 16.7 Simulation

Minutes ............................. 4.4

4.3 Predicted Flow and Sludge Accumulation along Tank Center at 1 Hour and

23 Simulation Minutes . . . . . . . . . . . . . . . . . . . .

4.4 Predicted Sludge Accumulation Pattern on Tank Bottom at 1 Hour and

23 Simulation Minutes $\ldots \ldots \ldots \ldots \ldots \ldots \ldots \ldots \ldots . \ldots \ldots$

4.5 Predicted Sludge Accumulation Pattern $1 \mathrm{ft}$ above Tank Bottom at

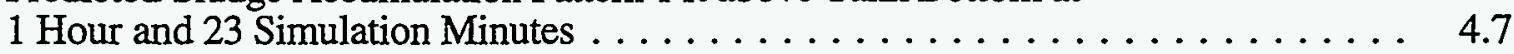

4.6 Predicted Sludge Accumulation Pattern $2 \mathrm{ft}$ above Tank Bottom at 1 Hour

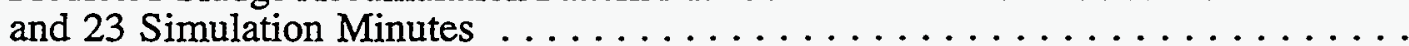

4.7 Diluent Injection and Supernate Withdrawal in a 19-ft-Long $\mathrm{x} 20$-ft-Wide

x 22-ft-High Rectangular Tank with Erosion-Resisting Sludge $\ldots \ldots \ldots \ldots .4 .10$

4.8 Predicted Jet Penetration into Sludge along Tank Center at 1 Simulation Second $\ldots \quad 4.11$

4.9 Predicted Velocity and Sludge Erosion Horizontal Pattern $4 \mathrm{ft}$ above

Tank Bottom at 1 Simulation Second $\ldots \ldots \ldots \ldots \ldots \ldots \ldots \ldots \ldots .12$

4.10 Three-Dimensional Distributions of Predicted Velocity and Sludge Erosion

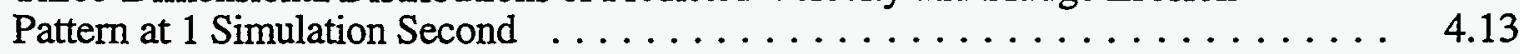

4.11 Three-Dimensional Distributions of Predicted Velocity and Sludge Erosion

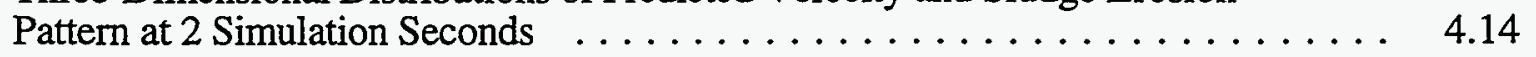

4.12 Three-Dimensional Distributions of Predicted Velocity and Sludge Erosion

Horizontal Pattern at 20 Simulation Seconds $\ldots \ldots \ldots \ldots \ldots \ldots \ldots \ldots . .15$

4.13 Three-Dimensional Distributions of Predicted Velocity and Sludge Erosion

Horizontal Pattern at 1 Simulation Hour $\ldots \ldots \ldots \ldots \ldots \ldots \ldots \ldots . .16$

4.14 Pump Jet Mixing in a 19-ft-Long x 20-ft-Wide x 22-ft-High Rectangular Tank

with Erosion-Resisting Sludge $\ldots \ldots \ldots \ldots \ldots \ldots \ldots \ldots \ldots \ldots \ldots \ldots \ldots \ldots \ldots .18$

4.15 Predicted Jet Penetration into Sludge along Tank Center at 1 Simulation Second . . 4.19

4.16 Predicted Velocity and Horizontal Sludge Erosion Pattern $4 \mathrm{ft}$ above

the Tank Bottom at 1 Simulation Second 
4.17 Predicted Jet Penetration into Sludge along Tank Center at 5 Simulation Seconds _ . 4.21

4.18 Predicted Jet Penetration into Sludge along Tank Center at 1 Simulation Minute $\quad \ldots 4.22$

4.19 Predicted Velocity and Horizontal Sludge Erosion Pattern $4 \mathrm{ft}$ above Tank Bottom at 1 Simulation Minute $\ldots \ldots \ldots \ldots \ldots \ldots \ldots . \ldots \ldots$

4.20 Predicted Jet Penetration into Sludge along Tank Center at 5 Simulation Minutes _ . 4.24

4.21 Predicted Velocity and Sludge Erosion Pattern along Tank Center at 15 Simulation Minutes . . . . . . . . . . . . . . . . . 4.25

4.22 Predicted Velocity and Horizontal Sludge Erosion Pattern $4 \mathrm{ft}$ above Tank Bottom at 15 Simulation Minutes . . . . . . . . . . . . . 4.26

\section{Tables}

2.1 Density Correlation for Multicomponent Tank Waste Supernatant Liquid

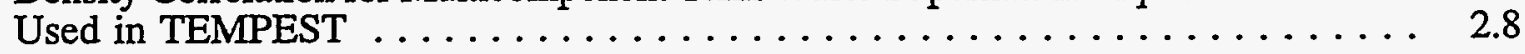

2.2 Viscosity Forms for Newtonian and Non-Newtonian Fluids in TEMPEST Code $\ldots \quad 2.9$ 


\subsection{Introduction}

Computational modeling has been used to address many tank waste retrieval operational and safety questions. These model applications include simulations of waste mobilization, mixing, gas retention, and chemical reactions. As a part of these modeling efforts, the TEMPEST code has been applied to Tanks 241-SY-101, SY-102, AZ-101, C-106 and AY-102 at the Hanford Site in Washington State, as well as tanks at Oak Ridge National Laboratory in Tennessee and Idaho National Engineering and Environmental Laboratory in Idaho (Terrones and Eyler 1993; Meyer 1994; Whyatt et al. 1996; Onishi et al. 1996a; Onishi and Recknagle 1997).

A planned approach for retrieving wastes in double-shell underground storage tanks at the Hanford Site is to use one or two mixer pumps to blend the sludge and supernatant/diluent to a nearly uniformly mixed slurry (see Figure 1.1). The resulting waste will then be pumped out from the tank.

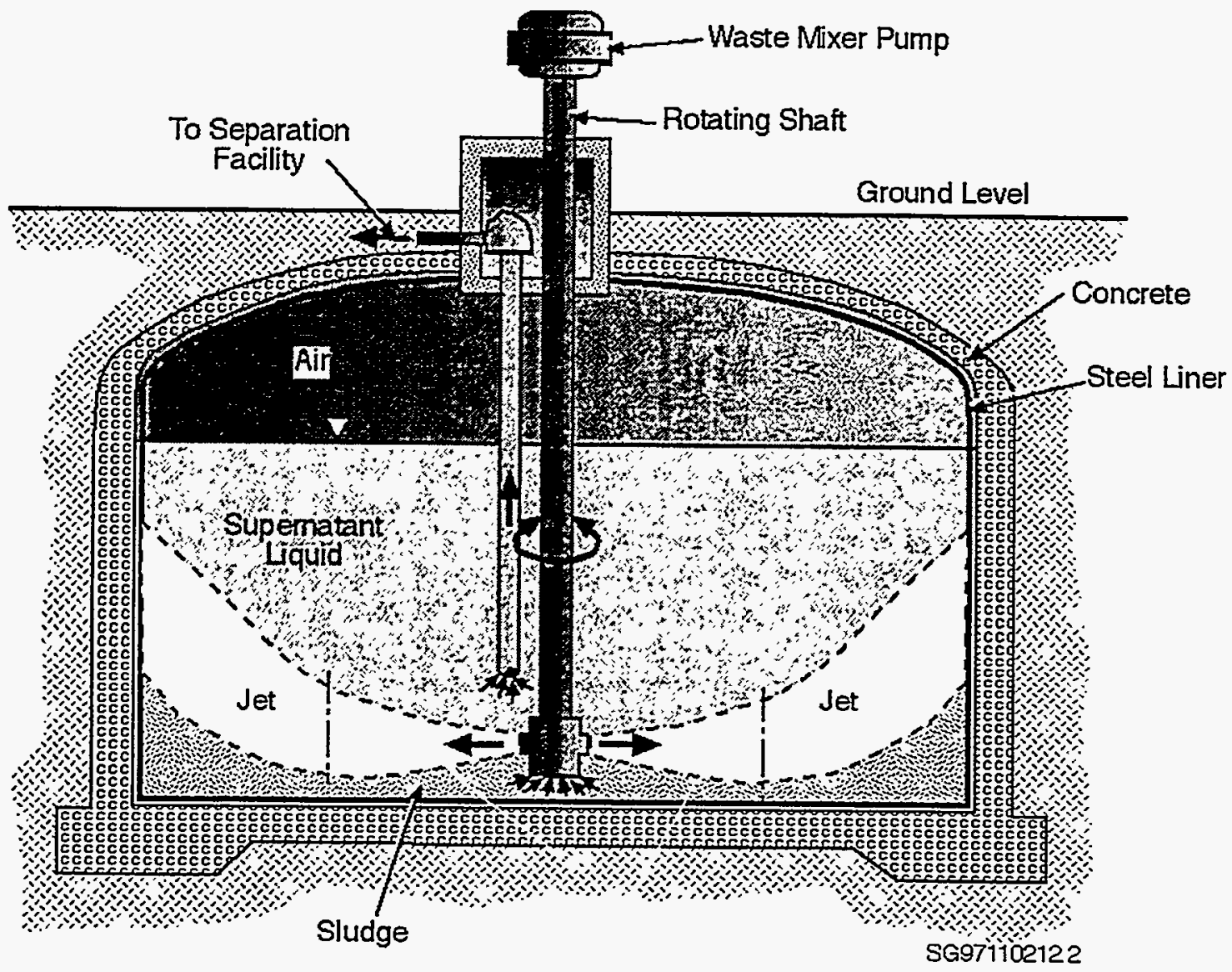

Figure 1.1. Sludge Pump Jet Mixing 
As shown in Figure 1.2 (Powell et al. 1997), the amount of sludge retrieved from the tank bottom may be linearly proportional to the shear stress acting on the sludge once it overcomes the yield strength of the sludge. It is thus important to model jet-induced flow shear stresses and sludge yield strength (critical shear stress) to simulate retrieval of erosion-resisting tank sludges.

This report describes current efforts on

- TEMPEST modifications needed to simulate mobilization and settling/demobilization of erosion-resisting tank sludges

- Testing the modified code's ability to predict sludge erosion, mobilization, immobilization, and/or remobilization caused by jet-induced flows.

Section 2 of this report describes the TEMPEST code formulation and modeling capabilities. The calculational procedure is discussed in Section 3, while the model testing results are reported in Section 4. The summary and conclusions are presented in Section 5, with cited references listed in Section 6.

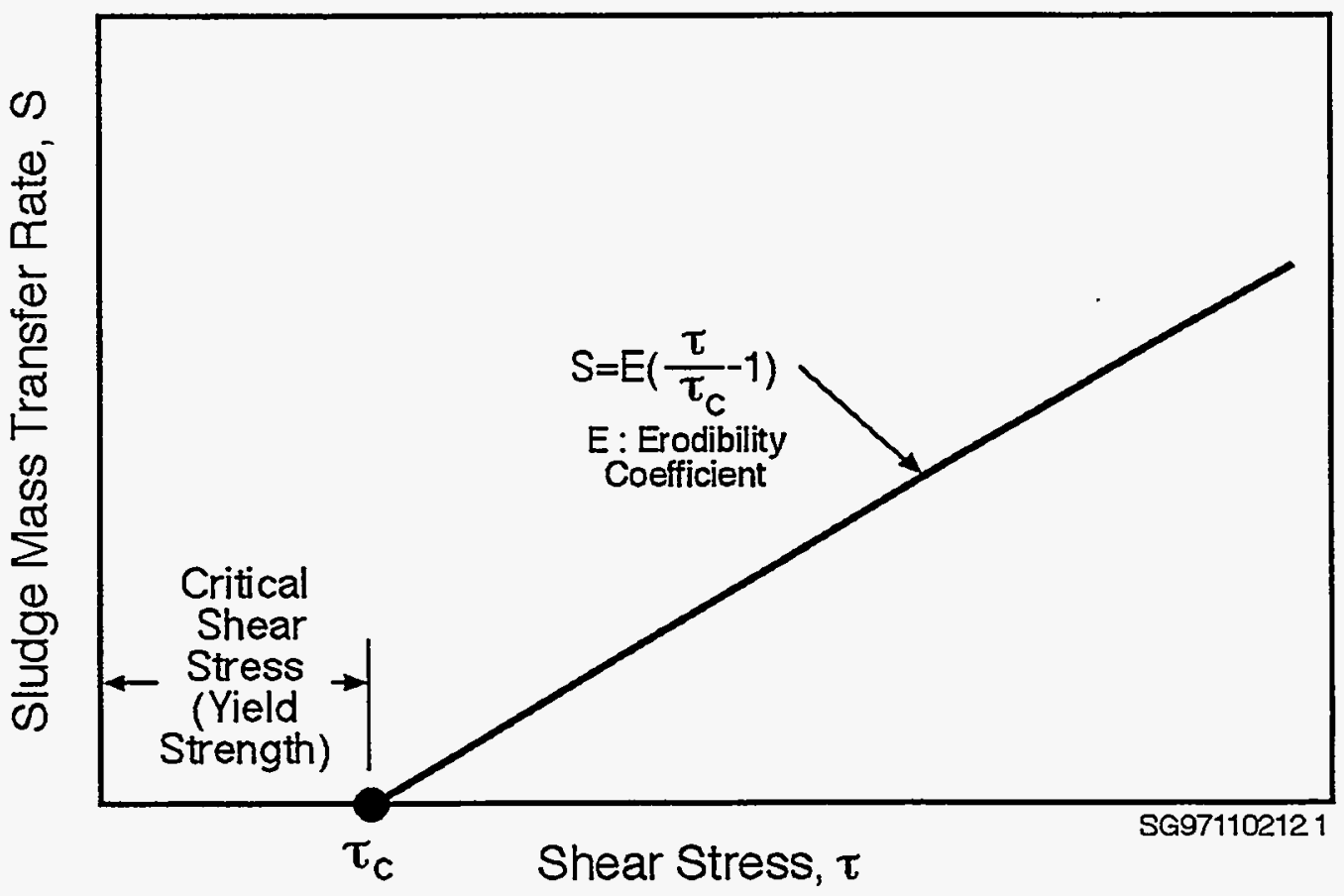

Figure 1.2. Sludge Erosion Versus Shear Stress 


\subsection{TEMPEST Description}

TEMPEST is a time-dependent, three-dimensional, finite volume, computational fluid dynamic code with reactive chemistry (Trent and Eyler 1994; Onishi et al. 1996b). It simulates flow, mass and energy transport, equilibrium and kinetic chemical reactions, and changes in fluid properties/rheology resulting from chemical and hydrodynamic processes. Thus TEMPEST explicitly accounts for the interactions of aqueous chemical reactions, dissolution/precipitation, adsorption/desorption, gaseous chemical reactions, and the associated rheology changes to simulate advective motion of physical and chemical species, solid settling/resuspension, and gas retention relevant to Hanford waste tanks.

\subsection{Fluid Dynamics}

The fluid dynamic portion of TEMPEST simulates flow, turbulence, and heat/mass transport and can accommodate Newtonian and non-Newtonian power-law fluids. Transport of multiple liquid, gas bubble, and solid species can be modeled. The thermal energy solution accommodates fully coupled heat transfer in liquids, gases, and solids.

TEMPEST uses the integral form of the fundamental conservation laws applied in the finite volume formulation. The governing conservation equations solved by TEMPEST are given below using tensor notation:

- Conservation of mass (continuity)

$$
\frac{\partial}{\partial \mathrm{t}} \int_{c v} \rho \mathrm{dV}+\int_{c s} \rho U_{s} d A_{s}=0
$$

- Conservation of momentum (Newton's second law)

$$
\frac{\partial}{\partial t} \int_{c v} \rho U_{r} d V+\int_{c s}\left(\rho U_{r} U_{s}+j_{\mu s}\right) d A_{s}=\dot{S}_{\mu}+F_{r}
$$

- Conservation of energy (first law of thermodynamics)

$$
\frac{\partial}{\partial t} \int_{c v} \rho e d V+\int_{c s}\left(\rho U_{s} h+j_{q s}\right) d A_{s}=S_{q}
$$

- Conservation of turbulent kinetic energy, $\mathrm{k}$

$$
\frac{\partial}{\partial t} \int_{c v} \rho k d V+\int_{c s}\left(\rho U_{s} k+j_{k s}\right) d A_{s}=S_{k}
$$


- Conservation of turbulent kinetic energy dissipation

$$
\frac{\partial}{\partial t} \int_{c v} \rho \varepsilon d V+\int_{c s}\left(\rho U_{s} \varepsilon+\dot{j}_{\varepsilon s}\right) d A_{s}=\dot{S}_{\varepsilon}
$$

- Conservation of mass constituents, $\mathrm{C}_{\mathrm{i}}$

$$
\frac{\partial}{\partial t} \int_{c v} \rho C_{i} d V+\int_{c s}\left(\rho\left(U_{s}+U_{i}\right) C_{i}+j_{C_{i}}\right) d A_{s}=S_{C_{i}}
$$

where

$$
\begin{array}{ll}
\mathrm{A}_{\mathrm{s}} & =\text { area in the coordinate direction } \mathrm{s} \\
\mathrm{C}_{\mathrm{i}} & =\text { mass concentration (partial density) of constituent } \mathrm{i} \\
\mathrm{cs}, \mathrm{cv} & =\text { control surface and volume, respectively } \\
\mathrm{e} & =\text { internal energy } \\
\mathrm{F}_{\mathrm{r}} & =\text { force component in the coordinate direction } \mathrm{r} \\
\mathrm{g}_{\mathrm{r}} & =\text { gravitational component in the coordinate direction } \mathrm{r} \\
\mathrm{h} & =\text { enthalpy } \\
\mathbf{j}_{\mathrm{xs}} & =\text { diffusive flux for conserved quantity } \mathrm{x} \text { in the } \mathrm{s} \text { coordinate direction }(\mu \text { and } \mathrm{q} \text { as } \\
\mathrm{k} & \mathrm{x} \text { are momentum and heat) } \\
\mathrm{r} & =\text { tensulent kinetic energy } \\
\mathrm{S} & =\text { tensor summation index (used as a free index), } \mathrm{s}=1,2,3 \\
\mathrm{~S}_{\mathrm{c}} & =\text { source term for mass constituent } \mathrm{i} \\
\mathrm{S}_{\mathrm{i}} & =\text { source term for turbulent kinetic energy } \\
\mathrm{S}_{\mu} & =\text { source term for momentum } \\
\mathrm{S}_{\mathrm{q}} & =\text { source term for thermal energy } \\
\dot{S}_{\varepsilon} & =\text { source term for dissipation of turbulent kinetic energy } \\
\mathrm{U}_{\mathrm{r}} & =\text { velocity component in the coordinate direction } \mathrm{r} \\
\mathrm{U}_{\mathrm{i}} & =\text { slip velocity of constituent } \mathrm{i} \\
\mathrm{t} & =\text { time } \\
\mathrm{V} & =\text { volume } \\
\mathrm{X}_{\mathrm{r}} & =\mathrm{r} \text { th space coordinate } \\
\varepsilon & =\text { turbulent kinetic energy dissipation } \\
\mathrm{\rho} & =\text { density. }
\end{array}
$$

The flux terms $\mathbf{j}_{\mathrm{xs}}$ used in above equations are gradient functions of the conservative quantity, x. In general, the transport coefficient (e.g., diffusivity or conductivity) for each of these relationships is a tensor quantity that reflects the anisotropic behavior of the transport media. For conservation of momentum,

$$
\mathbf{j}_{\mu s}=-\mu \frac{\partial U_{s}}{\partial X_{r}}
$$

where $\mu$ is viscosity. 
For mass diffusion (Fick's law), the flux, $\mathbf{j}_{c_{i} s}$, is defined as

$$
\mathbf{j}_{c_{s}}=-D_{i} \frac{\partial U_{s}}{\partial X_{r}}
$$

where $D_{i}$ is the diffusion coefficient for the constituent $i$. For turbulent flow, $D_{i}$ is set to the same value for all constituents.

The slip velocity of solid particle $i$ is (Richardson and Zaki 1954; Jansen et al. 1979)

$$
\begin{aligned}
& \mathrm{U}_{\mathrm{i}}=\mathrm{w}_{\mathrm{o}} \\
& \mathrm{U}_{\mathrm{i}}=\mathrm{w}=\mathrm{w}_{\mathrm{o}}\left(1-\mathrm{C}_{\mathrm{vR}}\right)^{\alpha}
\end{aligned}
$$

where

$\mathrm{C}_{\mathrm{V} R}=$ ratio of total solid volume fraction to the packing factor.

$\mathrm{W}=$ hindered settling velocity

$\mathrm{w}_{\mathrm{o}}=$ particle fall velocity without solid concentration effects

$\alpha=$ constant.

\subsection{Chemistry}

The chemical reaction portion of the TEMPEST code simulates equilibrium and kinetic chemical reactions, solid dissolution/precipitation, and adsorption/desorption for aqueous, solid and gaseous species.

\subsubsection{Equilibrium Chemical Reactions}

TEMPEST's equilibrium chemistry routines calculate fast chemical reactions of systems composed of aqueous, pure solid, solid-solution, adsorbed, and gas phases. This capability was achieved by imbedding the equilibrium chemistry code, GMIN (Felmy 1995), in the original computational fluid dynamic TEMPEST code (Onishi et al. 1996b).

The mathematical algorithm for the equilibrium chemistry is based on a constrained minimization of the Gibbs free energy (Snoeyink and Jenkins 1980; Harvie et al. 1987). This approach is more numerically stable (reliably converges to a free energy minimum) than the massaction approach used in other common chemical equilibrium codes (Felmy 1990). The freeenergy minimization in the model is mathematically formulated as (Harvie et al. 1987; Felmy 1995)

$$
\text { Minimize } \quad G=\sum_{j=1}^{n s} \mu_{j} n_{j}
$$

subject to the following constraints: 
- mass-balance

$$
\sum_{j=1}^{n s} a_{j i} n_{j}=b_{i} \quad \text { for } i=1, m_{c}
$$

- charge-balance

$$
\sum_{j=1}^{n a s} z_{j} n_{j}=0
$$

- $\mathrm{n}_{\mathrm{j}} \geq 0 \quad$ for all chemical species $\mathrm{j}$

Symbols are defined as follows:

$$
\begin{array}{ll}
a_{\mathrm{ji}} & =\text { number of moles of component } \mathrm{i} \text { in chemical species } \mathrm{j} \\
\mathrm{b}_{\mathrm{i}} & =\text { total number of moles of chemical element } \mathrm{i} \\
\mathrm{G} & =\text { Gibbs free energy } \\
\mathrm{m}_{\mathrm{c}} & =\text { number of linearly independent mass-balance constraints } \\
\mathrm{ns} & =\text { total number of chemical species } \\
\mathrm{nas} & =\text { number of aqueous species } \\
\mathrm{n}_{\mathrm{j}} & =\text { number of moles of chemical species } \mathrm{j} \\
\mathrm{z}_{\mathrm{j}} & =\text { charge of chemical species } \mathrm{j} \text { in electrolyte solution phase } \mathrm{s} \\
\mu_{\mathrm{j}} & =\text { chemical potential of chemical species } \mathrm{j} .
\end{array}
$$

The model uses separate chemical potential equations for aqueous-phase, pure solid-phase, solidsolution, adsorbed-phase, and gas-phase chemical species (Felmy 1995).

In the aqueous phase modeling, the excess solution free energy is modeled by using the following Pitzer equations:

$$
\ln \gamma_{i}=\ln \gamma_{i}^{\mathrm{DH}}+\sum_{j} B_{i j} m_{j}+\sum_{j} \sum_{k} C_{i j k} m_{j} m_{k}+\cdots
$$

where

$$
\begin{array}{ll}
\mathrm{B}_{\mathrm{ij}} & =\begin{array}{l}
\text { phenomenological expression for each ion interaction depending on ionic } \\
\text { strength }
\end{array} \\
\mathrm{C}_{\mathrm{ij}} & =\begin{array}{l}
\text { phenomenological expression for each ion interaction, not depending on } \\
\text { ionic strength }
\end{array} \\
\mathrm{m}_{\mathrm{i}}, \mathrm{m}_{\mathrm{j}} & =\text { molecular mobility of chemical species } \mathrm{i} \text { and } \mathrm{j}, \text { respectively } \\
\gamma_{\mathrm{i}} & =\text { activity coefficient of chemical species } \mathrm{i} \\
\gamma_{\mathrm{i}} \mathrm{DH} & =\text { modified Debly-Huckel activity coefficient. }
\end{array}
$$

Since the Pitzer equations are valid for high ionic strengths (Harvie et al. 1987), the TEMPEST formulation is applicable to the Hanford tank waste chemical conditions. 
The TEMPEST code can also calculate the activity coefficient by using the following Davies empirical formulation, which was primarily derived from observations of the mean activity coefficients of 1:1 electrolytes (Felmy 1995):

$$
\ln \gamma_{i}=-A \gamma \ln (10) Z_{i}^{2}\left\{\frac{I^{0.5}}{1+I^{0.5}}-0.3 I\right\}
$$

where

$$
\begin{aligned}
& \mathrm{A}=\text { the Debly-Huckel term } \\
& \mathrm{I}=\text { ionic strength } \\
& \mathrm{Z}_{\mathrm{i}} \quad \text { = charge of chemical species } \mathrm{i}
\end{aligned}
$$

The activity coefficients for non-ideal, solid-solution phases are calculated using parameters of a polynomial expansion in mole fractions of the excess free energy of mixing. The free energy of adsorbed phase species is described by the triple-layer, site-binding adsorption model (Felmy 1990).

\subsubsection{Kinetic Chemical Reactions}

Slow-reacting precipitation/dissolution and redox reactions are handled by the kinetic chemistry model. For the kinetic reactions, the rate law, $\mathrm{R}$, expresses the concentration change of solid i with time:

$$
R_{i}=\frac{d\left[C_{s i}\right]}{d t}
$$

The TEMPEST code expresses the above rate law in the following form as described in Aagaard and Helgeson (1982), Steefel and van Cappellen (1990), and Steefel and Lasaga (1994):

$$
\mathrm{R}_{\mathrm{i}}=\left\{\text { sign of }\left(\log \frac{\mathrm{K}_{\mathrm{i}}}{\mathrm{Q}_{\mathrm{i}}}\right)\right\}\left\{\mathrm{k}_{\mathrm{i} 1}+\mathrm{k}_{\mathrm{i} 2}^{\prime} \text { (solids surface area) }\right\}\left|1-\left\{\frac{\mathrm{Q}_{\mathrm{i}}}{\mathrm{K}_{\mathrm{i}}}\right\}^{\mathrm{n}_{\mathrm{i}}}\right|^{l_{\mathrm{i}}}
$$

where

$$
\begin{array}{ll}
{\left[\mathrm{C}_{\mathrm{si}}\right]} & =\text { molality of solid } \mathrm{i} \\
\mathrm{K}_{\mathrm{i}} & =\text { equilibrium constant } \\
\mathrm{k}_{\mathrm{i} 1}, \mathrm{k}_{\mathrm{i} 2}{ }^{\prime}= & \text { reaction rates of solid } \mathrm{i}, \mathrm{k}_{\mathrm{i} 1} \text { being independent of the solid surface area and } \\
& \mathrm{k}_{\mathrm{i} 2} \text { depending on the amount of solid surface area } \\
\mathrm{l}_{\mathrm{i}}, \mathrm{n}_{\mathrm{i}}= & \text { positive constants usually determined empirically } \\
\mathrm{Q}_{\mathrm{i}}= & \text { activity product. }
\end{array}
$$

The above kinetic expression can be used for both elementary and non-elementary reaction cases. For simplicity, TEMPEST assigns $l_{i}=1$, and $n_{i}=1$, assuming that reactions are first order (Steefel and Lasaga 1994). Note that assignment of $l_{i}=n_{i}=1$ automatically provides the proper \{sign of $\left.\left(\log \mathrm{K}_{\mathrm{i}} / \mathrm{Q}_{\mathrm{i}}\right)\right\}$ from the term $\left\{1-\mathrm{Q}_{j} / \mathrm{K}_{\mathrm{i}}\right\}$ in Equation (2.18). 
Because solid surface area per unit weight of water is proportional to the amount of solids per unit weight of water, the code assumes that

solid surface area $=b_{s i}\left[C_{s i}\right]$

where $b_{\mathrm{si}}=$ constant. Thus the rate law (Equation 2.18 ) becomes

$$
\mathrm{R}_{\mathrm{i}}=\frac{\mathrm{d}\left[\mathrm{C}_{\mathrm{si}}\right]}{\mathrm{dt}}=\left\{\mathrm{k}_{\mathrm{i} 1}+\mathrm{k}_{\mathrm{i} 2}\left[\mathrm{C}_{\mathrm{si}}\right]\right\}\left\{1-\frac{\mathrm{Q}_{\mathrm{i}}}{\mathrm{K}_{\mathrm{i}}}\right\} \text {. }
$$

where $k_{\mathrm{i} 2}=b_{\mathrm{si}} k_{\mathrm{i} 2}$.

The corresponding rate law for associated aqueous species, $\mathrm{w}_{\mathrm{j}}$, then becomes

$$
\begin{aligned}
& \mathrm{R}_{\mathrm{wj}}=\frac{\mathrm{d}\left[\mathrm{C}_{\mathrm{wj}}\right]}{\mathrm{dt}}=\mathrm{a}_{\mathrm{i}}\left\{\mathrm{k}_{\mathrm{i} 1}+\mathrm{k}_{\mathrm{i} 2}\left[\mathrm{C}_{\mathrm{si}}\right]\right\}\left\{1-\frac{\mathrm{Q}_{\mathrm{i}}}{\mathrm{K}_{\mathrm{i}}}\right\} \\
& \mathrm{R}_{\mathrm{wj}}=\mathrm{a}_{\mathrm{i}} \frac{\mathrm{d}\left[\mathrm{C}_{\mathrm{si}}\right]}{\mathrm{dt}}
\end{aligned}
$$

where

$$
\begin{array}{ll}
a_{i} & =\text { moles of species in one mole of solid } \mathrm{i} \\
{\left[C_{w j}\right]} & =\text { molality of aqueous chemical species } j .
\end{array}
$$

In general, these equations are coupled nonlinear ordinary differential equations, because $\mathrm{K}_{\mathrm{i}}$ and $\mathrm{Q}_{\mathrm{i}}$ are functions of all chemical concentrations relevant to precipitation/dissolution of solid i.

Values of $\mathrm{K}_{\mathrm{i}}$ and $\mathrm{Q}_{\mathrm{i}}$ are calculated by the equilibrium chemical modeling portion of the TEMPEST code. These values change with time and space during the simulation period. If the TEMPEST time steps are small (e.g., milliseconds), $\mathrm{K}_{\mathrm{i}}$ and $\mathrm{Q}_{\mathrm{i}}$ may be assumed constant over one time step or a limited number of these time steps. Under this assumption, Equation (2.20) becomes a set of decoupled ordinary differential equations with known values of $\mathrm{K}_{\mathrm{i}}$ and $\mathrm{Q}_{\mathrm{i}}$ for each of the precipitation/dissolution reactions and can be solved numerically or analytically.

For non-zero $\mathrm{k}_{\mathrm{i} 2}$ values, an analytical solution of Equation (2.20) is

$$
C_{s i}=\frac{\left.\left\{k_{i 1}+k_{i 2} C_{s 0 i}\right] \exp \left\{-\left(1-\frac{Q_{i}}{K_{i}}\right) k_{i 2} t\right\}-k_{i 1}\right\}}{k_{i 2}}
$$

where $\mathrm{C}_{\mathrm{s} 0 \mathrm{i}}$ is the initial concentration of solid $\mathrm{i}$.

When $\mathrm{k}_{\mathrm{i} 2}$ equals zero, the analytical solution of Equation (2.20) becomes 


$$
C_{s i}=-k_{i 1}\left\{1-\frac{Q_{i}}{K_{i}}\right\} t+C_{s 0 i}
$$

TEMPEST uses Equations (2.22), (2.23), and (2.24) to simulate the kinetic chemical reactions. In addition, the Hamming numerical method is used by TEMPEST when kinetic reaction equations are expressed by coupled linear ordinary differential equations.

\subsection{Physical Properties and Rheology}

Formulations and correlations for physical properties and rheology or tank wastes have been developed and incorporated into TEMPEST (Mahoney and Trent 1995). They include the properties of density, viscosity, shear stress, sludge strength, thermal conductivity, specific heat, gas bubble, and solid particle drag for supernatant liquid and slurries (Trent and Eyler 1994).

The physical property models in TEMPEST have two basic templates: 1) supernatant physical properties and rheology dependent on concentrations of aqueous chemical species and solution temperature and 2) properties of the slurry depending on solution properties and solid concentration. For example, the TEMPEST code calculates the supernatant density by (Onishi et al. 1995):

$$
\rho_{1}=a_{0}+a_{1} C+a_{2} C^{2}+a_{3} C^{3}+\frac{a_{4}}{T}+a_{5} C T+a_{6} T^{2}
$$

where

$$
\begin{aligned}
& \mathrm{a}_{\mathrm{k}}=\text { coefficients obtained by data correlation } \\
& \mathrm{C}=\text { total concentration of all solutes in weight percent of the total solution } \\
& \mathrm{T}=\text { solution temperature }(\mathrm{K}) \\
& \rho_{1}=\text { supernatant density }\left(\mathrm{kg} / \mathrm{m}^{3}\right)
\end{aligned}
$$

Specific values of $a_{k}$ are shown in Table 2.1 (Mahoney and Trent 1995). TEMPEST has also built-in, direct look-up tables for values of some common fluids that are a function of temperature and, in some cases, chemical concentrations (e.g., salt water as a function of temperature and salinity). TEMPEST can also accept the solution density as a known input value. The slurry (mixture of solution and solids) density is determined by

$$
\rho_{m}=\left(1-C_{v s}\right) \rho_{1}+C_{v s} \rho_{s}
$$

where

$$
\begin{aligned}
& C_{v s}=\text { total solid volume fraction } \\
& \rho_{m}=\text { density of slurry } \\
& \rho_{s}=\text { average density of total solids. }
\end{aligned}
$$


Table 2.1. Density Correlation $\left(\mathrm{kg} / \mathrm{m}^{3}\right)$ for Multicomponent Tank Waste Supernatant Used in TEMPEST

\begin{tabular}{|l|l|l|l|l|l|l||}
\hline \hline$a_{0}$ & $\mathrm{a}_{1}$ & $\mathrm{a}_{2}$ & $\mathrm{a}_{3}$ & $\mathrm{a}_{4}$ & $\mathrm{a}_{5}$ & $\mathrm{a}_{6}$ \\
\hline 1245.8 & 9.824 & 0 & -1.0606 & 0 & 0 & $6.812 \times 10^{-4}$ \\
\hline
\end{tabular}

Liquid-solid-gas slurry densities are computed by

$$
\rho_{m}=\left(1-C_{v s}-C_{v g}\right) \rho_{1}+C_{v s} \rho_{s}
$$

where $C_{v g}=$ gas volume fraction.

TEMPEST accommodates various viscosity models of Newtonian and non-Newtonian fluids. Their general form is

$$
\mu_{\mathrm{eff}}=\mathrm{f} \cdot \dot{\gamma}^{\mathrm{g}}
$$

where

$\mathrm{f}, \mathrm{g}=$ functions and values defined in Table 2.2

$\mu_{\text {eff }} \quad=$ viscosity

$\dot{\gamma} \quad=$ strain rate.

Similar to the liquid density discussed above, the fluid viscosity may be taken from a library of pure fluids or may be initialized by the model user as a function of temperature and aqueous chemical species concentration (Mahoney and Trent 1995).

TEMPEST calculates shear stress for Newtonian fluids as

$$
\tau=\mu_{\text {eff }} \cdot \dot{\gamma}
$$

In TEMPEST, the sludge viscosity and yield strength are treated separately. The sludge viscosity is used in the viscous terms of the Navier-Stokes equations, whereas the yield strength, $F_{y i}$, is treated as a term that resists the shear and normal stresses of a fluid flow. Calculation of the yield strength and the procedure for simulating non-Newtonian flow with yield stress is described in Section 3.

\subsection{Modeling Sequence}

The above equations were incorporated into TEMPEST to account for interactions of chemical reactions, associated rheology changes, and tank waste movements. The chemical model can be called at every simulation time step or at prescribed time-step intervals. The TEMPEST modeling sequence within a time step is 
Table 2.2. Viscosity Forms for Newtonian and Non-Newtonian Fluids in the TEMPEST Code (Trent and Eyler 1994; Trent and Mahoney 1995)

\begin{tabular}{|c|c|c|}
\hline $\mathrm{f}$ & $\mathrm{g}$ & Description \\
\hline$\mu$ & 0 & $\begin{array}{l}\text { Newtonian without solid } \\
\text { concentration dependence }\end{array}$ \\
\hline$\mu\left\{1+\left(\mathrm{k}_{1}\right)^{\beta} \mathrm{k}_{2}\right\}$ & 0 & $\begin{array}{l}\text { Newtonian with solid } \\
\text { concentration dependence: } \\
\text { power shape }\end{array}$ \\
\hline$\mu\left(k_{1}\right)^{\beta}$ & 0 & $\begin{array}{l}\text { Newtonian with solid } \\
\text { concentration dependence: } \\
\text { exponential shape }\end{array}$ \\
\hline $\mathrm{K}$ & $\mathrm{m}$ & $\begin{array}{l}\text { Power law: } \\
\text { Ostwald-DeWaele model }\end{array}$ \\
\hline $\mathrm{K}\left\{1+\left(\mathrm{k}_{1}\right)^{\beta} \mathrm{k}_{2}\right\}$ & $\mathrm{m}$ & $\begin{array}{l}\text { Power law: } \\
\text { Ostwald-DeWaele model } \\
\text { power shape }\end{array}$ \\
\hline $\mathrm{K}\left(\mathrm{k}_{1}\right)^{\beta}$ & $\mathrm{m}$ & $\begin{array}{l}\text { Power law: } \\
\text { Ostwald-DeWaele model } \\
\text { exponential shape }\end{array}$ \\
\hline $\mathrm{K}\left\{1+\left(\mathrm{k}_{1}\right)^{\beta}+\left(\mathrm{k}_{2}\right)^{\beta}+\left(\mathrm{k}_{3}\right)^{\beta}\right\}$ & 0 & Cubic power shape \\
\hline 1 & $\mathrm{~m}\left\{1+\left(\mathrm{k}_{1}\right)^{-\beta}+\left(\mathrm{k}_{2}\right)^{-\beta}\right\}-1$ & $\begin{array}{l}\text { Power law with solid } \\
\text { concentration dependence: } \\
\text { double exponential form }\end{array}$ \\
\hline
\end{tabular}

1) simulate flow and transport

If the chemistry routines are called (otherwise Steps 2 through 4 are skipped)

2) calculate fast chemical reactions with the equilibrium chemical submodel

3) calculate slow kinetic chemical reactions within the time step with the kinetic chemical submodel

4) recalculate fast chemical reactions with the equilibrium chemical submodel to reflect the changes produced by the slow kinetic chemical reactions obtained in Step 3

5) calculate physical properties and rheology.

Repeat this procedure at each time step until the simulation time requested by the user is reached. 


\subsection{Code Modifications for Erosion of Immobile Material}

This section provides an overview of the approach taken in the TEMPEST code for modeling immobile sludge layers and how the effects of fluid shear stresses are used to compute sludge layer erosion. TEMPEST solves the appropriate physical balance equations using a finite volume approach, and thus physical quantities computed are volume averages for each finite volume. On the other hand, erosion caused by flow shear is a surface phenomenon that can be depicted as an interface between the flowing fluid and the eroding immobile sludge material. The interface might be simulated as a moving front because the interface is continually moving with time at a rate dependent upon the properties of the immobile material and magnitude of the local fluid shear stress.

Simulating a moving erosion front is computationally very difficult, and each simulation would require a great amount of computer time. Theoretically, the solutions should be accurate as long as the sludge material properties can be accurately characterized. However, the material properties of the sludge are not well understood, and it does not appear reasonable to heavily invest in a sophisticated erosion model that would require large amounts of computer time with only marginally improved accuracy.

For these reasons, we have chosen a more appropriate approach which is to develop erosion criteria based on the finite volume approach used in TEMPEST. These criteria are based generally on the cell volume's mechanical strength (yield strength) and the cell interfacial fluid shear forces. Once the erosion criteria have been met for a particular computational cell, deterioration (reduction) of material strength and viscosity begins, and the cell is eroded over a relatively short period of time.

\section{Approaches}

The momentum equation (Equation 2.2) simulated by TEMPEST is given in a Cartesian tensor form as

$$
\begin{aligned}
& \frac{\partial\left(\rho U_{r}\right)}{\partial t}+\frac{\partial}{\partial X_{s}}\left(\rho U_{s} U_{r}\right)=-\frac{\partial P}{\partial X_{r}}+\rho g_{r}+\frac{\partial}{\partial X_{s}}\left[\mu\left(\frac{\partial U_{r}}{\partial X_{s}}+\frac{\partial U_{s}}{\partial X_{r}}\right)\right]-F_{r}\left(U_{r}\right) \\
& \text { Viscous Forces Flow Drag Force. }
\end{aligned}
$$

where the tensor index $r$ defines the coordinate direction $(r=1,2,3)$, and $s$ is a summation index.

There are two terms in this equation that might be used in TEMPEST to approximate sludge immobility and erosion:

1. sludge viscous forces

2. flow drag forces.

Various attempts have been made to develop immobilization criteria using the viscous force term (the first approach) in the equations of motion (Equation 3.1), without success. Generally, 
over the long term the sludge pile will collapse regardless of the initial mechanical strength. Thus using viscous effects to model sludge immobilization and erosion has been abandoned in favor of using the flow drag term (the second approach) as given in Equation (3.1). The TEMPEST approach is basically as follows:

1. Compute the rate of strain tensor, $\dot{\gamma}_{i, j}$, and the second invariant, $\Pi$.

The second invariant of the strain rate tensor is computed as

$$
\Pi=\sqrt{\dot{\gamma}^{2}}
$$

where

$$
\dot{\gamma}^{2}=\dot{\gamma}_{1,1}^{2}+\dot{\gamma}_{2,2}^{2}+\dot{\gamma}_{3,3}^{2}+\dot{\gamma}_{1,2}^{2}+\dot{\gamma}_{1,3}^{2}+\dot{\gamma}_{2,3}^{2}
$$

The rate of strain, $\dot{\gamma}_{\mathrm{ij}}$, is defined by

$$
\dot{\gamma}_{i, j}=\left(\frac{\partial U_{i}}{\partial X_{j}}+\frac{\partial U_{j}}{\partial X_{i}}\right)
$$

2. Compute volume fractions for particulate solid materials, $\mathrm{C}_{\mathrm{v} i \mathrm{i}}$, and the relative total volume fraction, $C_{V R}$, where $i=1,2,3 \ldots$ number of solid constituents:

$$
C_{v R}=\frac{\sum_{i} C_{v i}}{C_{v \max }} . \quad 0 \leq C_{v R} \leq 1
$$

where $\mathrm{C}_{\mathrm{v} \max }=$ the solid volume packing factor, which is the maximum total solid volume fraction (in the absence of gas).

3. Compute the sludge material mechanical strength according to Ellwood et al. (1990):

$$
F_{y i}=\tau_{0}\left(1-e^{-n C_{v R}}\right) \frac{\left(1-e^{-m \Pi}\right)}{\Pi} \dot{\gamma}_{i, j=1,2,3}
$$

where

$\tau_{0}=$ zero-strain yield strength of the sludge (fully packed and static)

$\mathrm{n}=$ moisture content exponential shape factor

$\mathrm{m}=$ strain rate exponential shape factor.

In this expression, a small increase in the moisture content and/or strain decreases the sludge mechanical strength. 
4. Once the yield strength, $\mathrm{F}_{\mathrm{y} i \mathrm{i}}$, has been computed, the following check is made:

- If the fluid shear stress at the interface of a fluid cell and an immobile cell exceeds the sludge mechanical strength calculated by Equation (3.6), the immobile cell is treated as an ordinary computational cell and begins to erode by strain and increasing moisture content.

- If the fluid shear stress at the interface of a fluid cell and an immobile cell is less than the sludge mechanical strength, the flow drag term, $\mathrm{F}_{\mathrm{r}}\left(\mathrm{U}_{\mathrm{r}}\right)$, in Equation (3.1) is set to a "large" number, and velocity changes computed for the sludge are set to zero.

This approach has been found to be effective in several test cases that have been run to date (see Section 4). The model has several sludge parameters and shape factors that are not well known. It is expected that modifications consistent with erosion data will define these parameters better and improve the reliability of the model's predictions. 


\subsection{Model Testing on Solids Accumulation and Erosion}

The newly developed sludge erosion/immobilization model has been implemented in the TEMPEST code and tested for a number of simplified three-dimensional tank conditions. These tests were performed with and without sludge yield strength and under a variety of other sludge and flow conditions.

These model tests show that sludges without yield strength were eventually entirely eroded by jet-induced flows. In sludges/slurries with yield strength, however, some solids remained immobile. To demonstrate the newly developed modeling capability, the following three model test results are presented:

1. Solid Deposition and Accumulation in a Tank

Test Purpose: 'to demonstrate that the model will allow heavy particles to accumulate in a "pile" on the tank floor and that the resulting sludge pile develops mechanical strength (yield strength) as it compacts from hindered solid settling.

\section{Diluent Jet Injection into Tank Sludge}

Test Purpose: to demonstrate that the model will compute fluid stress-induced erosion of a sludge layer; also, to show that the sludge, with its mechanical strength, will remain immobile when the normal and shear stresses induced by the fluid flow are less than the mechanical strength of the sludge.

\section{Sludge Pump Jet Mixing}

Test Purpose: to demonstrate that the model will compute sludge erosion and immobilization while contents of the tank are being mixed with a sludge pump.

In these cases, it was assumed that tanks were cube-shaped and that the sludge/slurry contained only one solid size fraction. These assumptions were made to simplify the test simulations and to expedite the model development and testing.

\subsection{Test Case 1: Solid Deposition and Accumulation in a Tank}

This test case simulated slurry being slowly injected into a $19 \times 19 \times 19$-ft tank (see Figure 4.1). Supernatant liquid with a density of $91 \mathrm{lb} / \mathrm{ft}^{3}\left(1,460 \mathrm{~kg} / \mathrm{m}^{3}\right)$ and a viscosity of $0.016 \mathrm{lb}_{\mathrm{m}} / \mathrm{ft}-\mathrm{sec}(24 \mathrm{cP})$ was assumed to fill the tank. The slurry injection nozzle is located at the tank lateral center at the elevation of the supernatant surface. A withdrawal pump with a 1-ftsquare opening is located at the opposite end of the tank (19 ft away from the injection nozzle); it removes supernate at the same volumetric rate as the slurry is injected. Figure 4.1 shows the slurry injection nozzle (top left) and the liquid withdrawal located on right side of the tank at the surface of the supernatant liquid. 
Plot at time $=0.010$ seconds

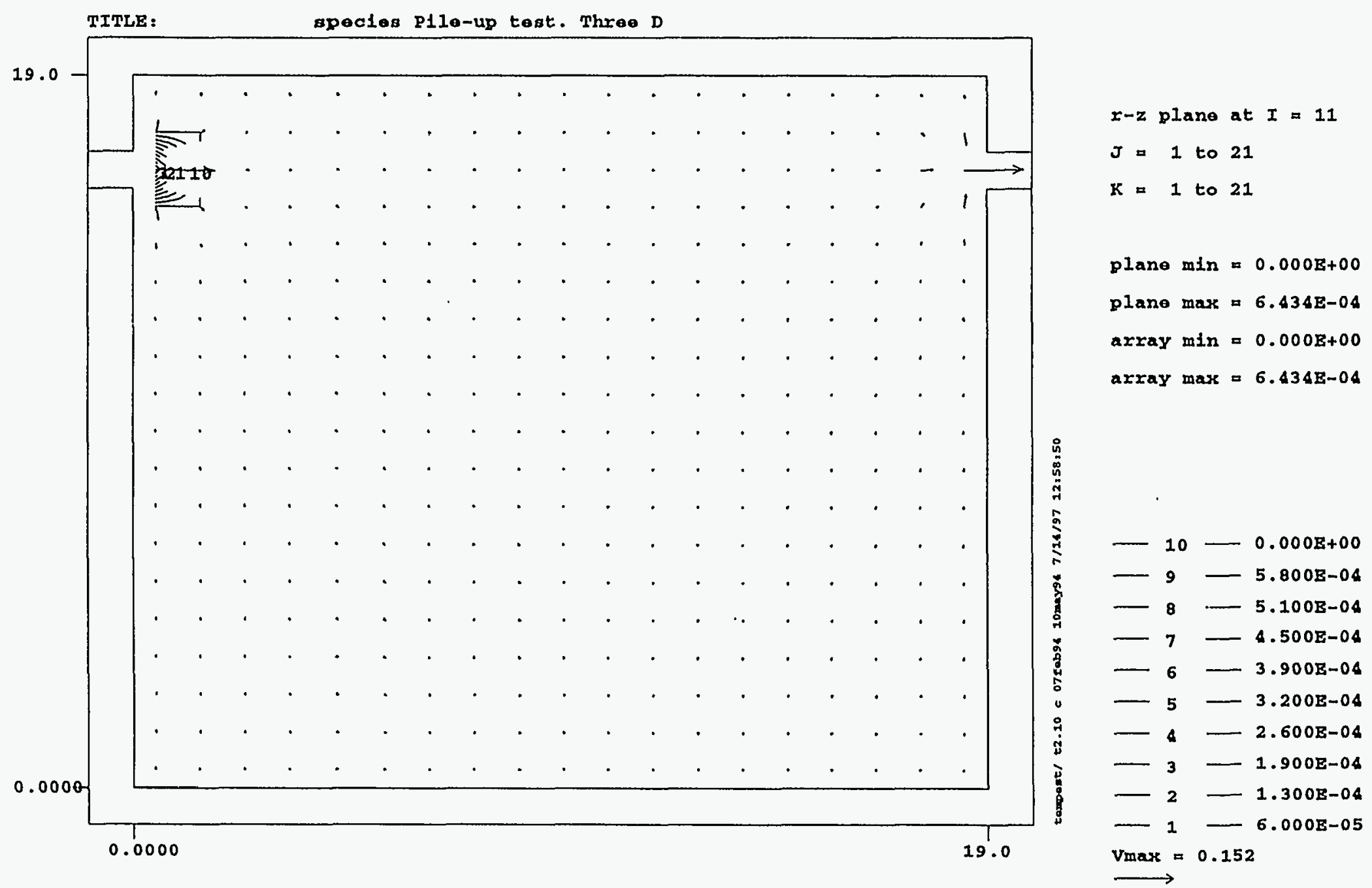

Figure 4.1. Injection and Withdrawal Nozzle Setup in a $19 \times 19 \times 19-\mathrm{ft}$ Tank 
The slurry is injected at a very slow velocity of $0.25 \mathrm{ft} / \mathrm{sec}(0.076 \mathrm{~m} / \mathrm{s})$. The solids density was assigned to be $136 \mathrm{lb}_{\mathrm{m}} / \mathrm{ft}^{3}\left(2,180 \mathrm{~kg} / \mathrm{m}^{3}\right)$. The injected slurry contains $35 \mathrm{lb} \mathrm{m}_{\mathrm{m}} / \mathrm{ft}^{3}\left(560 \mathrm{~kg} / \mathrm{m}^{3}\right)$ of the solids with a large unhindered settling velocity of $1.0 \mathrm{ft} / \mathrm{sec}(0.305 \mathrm{~m} / \mathrm{s})$ in supernate. The TEMPEST code calculated the solid's hindered settling velocity under high solid concentrations (e.g., within the sludge pile being developed with Equation 2.10. In this study, the value of $\alpha$ in this equation was selected to be 4.65 , which is appropriate for the Stokes Law range of particle settling (Richardson and Zaki 1954). As the simulation continued, the sludge pile compacted and gained mechanical strength. The sludge pile's computed mechanical strength varies with solid volume fraction and would reach the full mechanical strength of $10,000 \mathrm{~Pa}(1.5 \mathrm{psi})$ when it achieves a maximum solid packing of $46 \mathrm{vol} \%$. The mechanical strength of the sludge is calculated by Equation 3.6.

For this test, slurry was injected for the first 16.7 minutes. With the slow injection rate of heavy particles, TEMPEST predicted that the particles would almost immediately fall toward the tank bottom and pile up there, as shown in Figure 4.2 (at 16.7 minutes of slurry injection). At that time, TEMPEST predicted that the solids volume fraction had reached a maximum value of 41.6 vol\%.

After 16.7 minutes, the slurry injection was terminated. There is a substantial density difference between the sludge mound and the surrounding supernatant. This density difference results in a force that will spread the sludge pile laterally-unless the sludge pile has sufficient resisting mechanical strength (yield strength). At 1 hour and 23 simulation minutes (65 minutes after the termination of the slurry injection), TEMPEST predicts that the accumulated sludge pile remains motionless with a maximum solid volume fraction slightly increasing from 41.6 to 43.4 vol\%. This density increase (Figure 4.3) is caused by hindered particle settling within the sludge layers (albeit very slowly due to the significant slow-down of the settling within these very high solid concentration layers). Figure 4.3 also shows very small residual flow velocity of less than $0.04 \mathrm{ft} / \mathrm{sec}(1.2 \mathrm{~cm} / \mathrm{s})$. This slow-moving tank flow is too slow to erode the settled sludge.

The predicted sludge accumulations are shown in Figures 4.4 through 4.6 at the tank bottom and at elevations of $1 \mathrm{ft}$ and $2 \mathrm{ft}$ above the bottom, respectively. The maximum solid fraction within the pile at the tank bottom is 43.4 vol\%; at $1 \mathrm{ft}$ it is 42.6 vol\% and at $2 \mathrm{ft}$ from tank bottom, $29.5 \mathrm{vol} \%$. The sludge accumulated on the tank bottom has a cone shape spreading in a semicircle with its center approximately $3 \mathrm{ft}$ from the tank wall (injection point). These model test results demonstrate that the TEMPEST code is able to simulate the bottom accumulation of sludge and the development of the sludge pile's mechanical strength. 
Plot at time $=16.667$ minutes

TITLE:

species Plio-up teat. Throe D

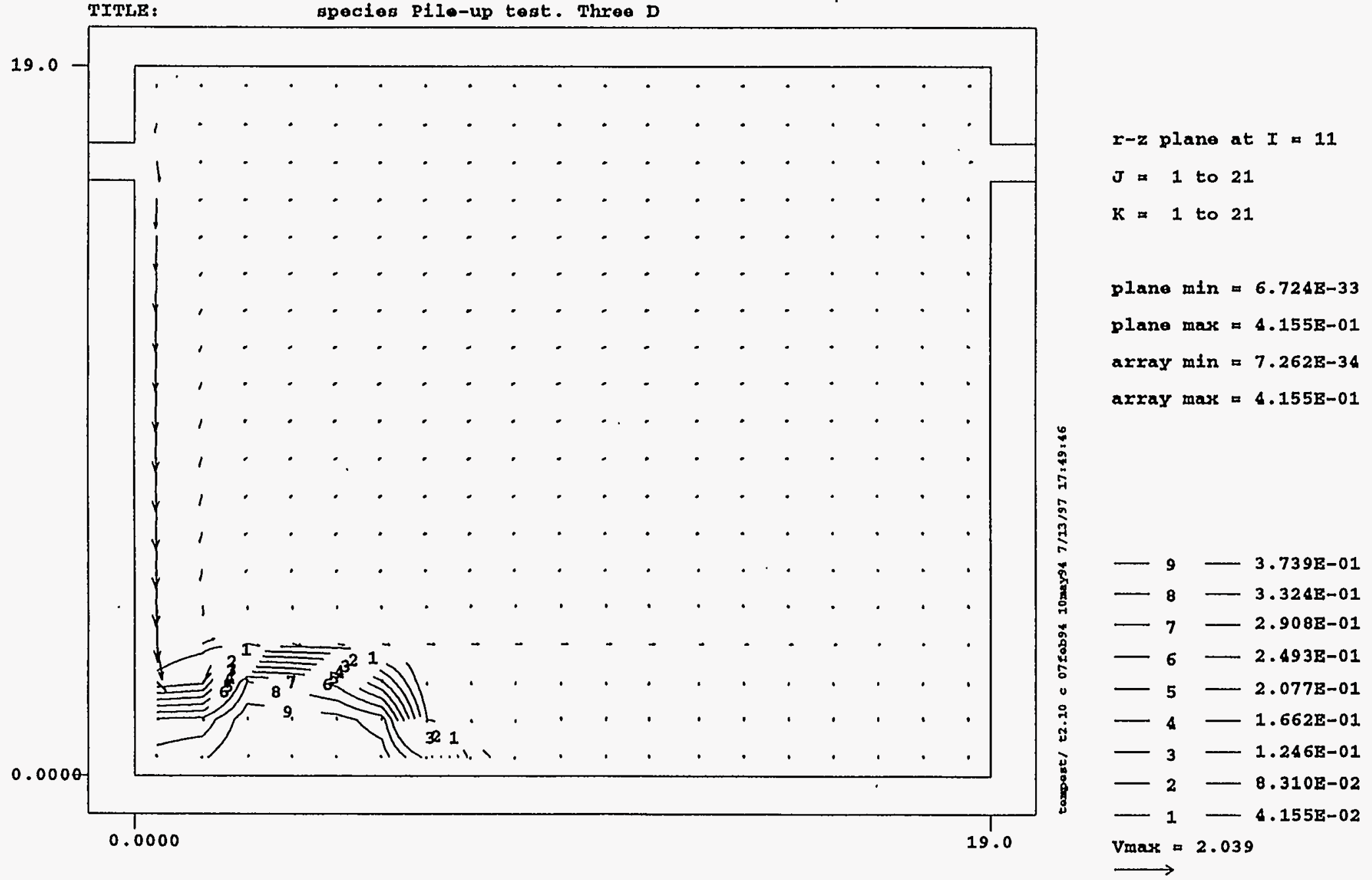

Figure 4.2. Predicted Flow (ft/sec) and Sludge Accumulation (shown in solid volume fraction) along the Tank Center at 16.7 Simulation Minutes 


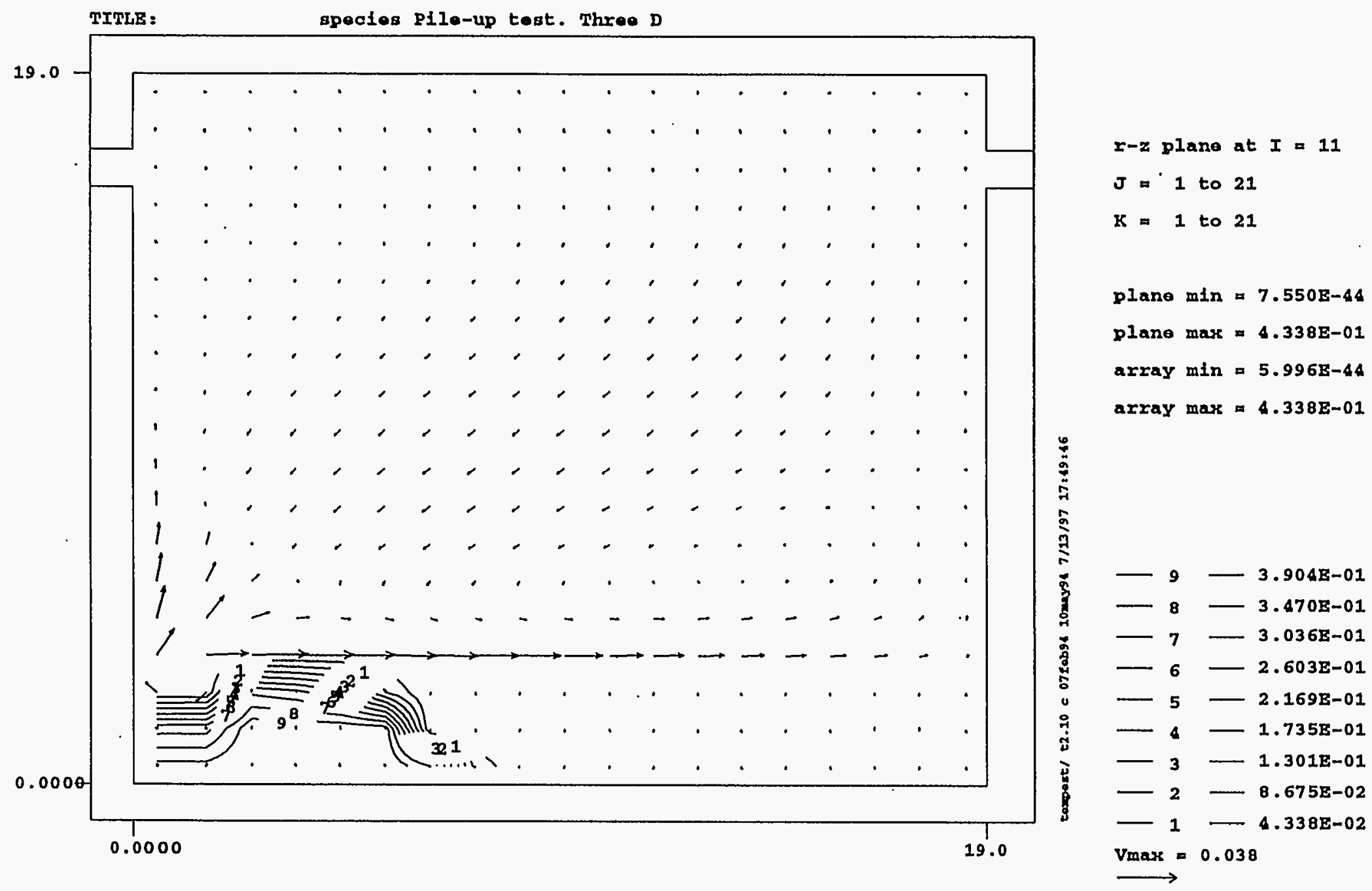

Figure 4.3. Predicted Flow (ft/sec) and Sludge Accumulation (shown in solid volume fraction) along Tank Center at 1 Hour and 23 Simulation Minutes 
Plot at timo $=1.389$ houra

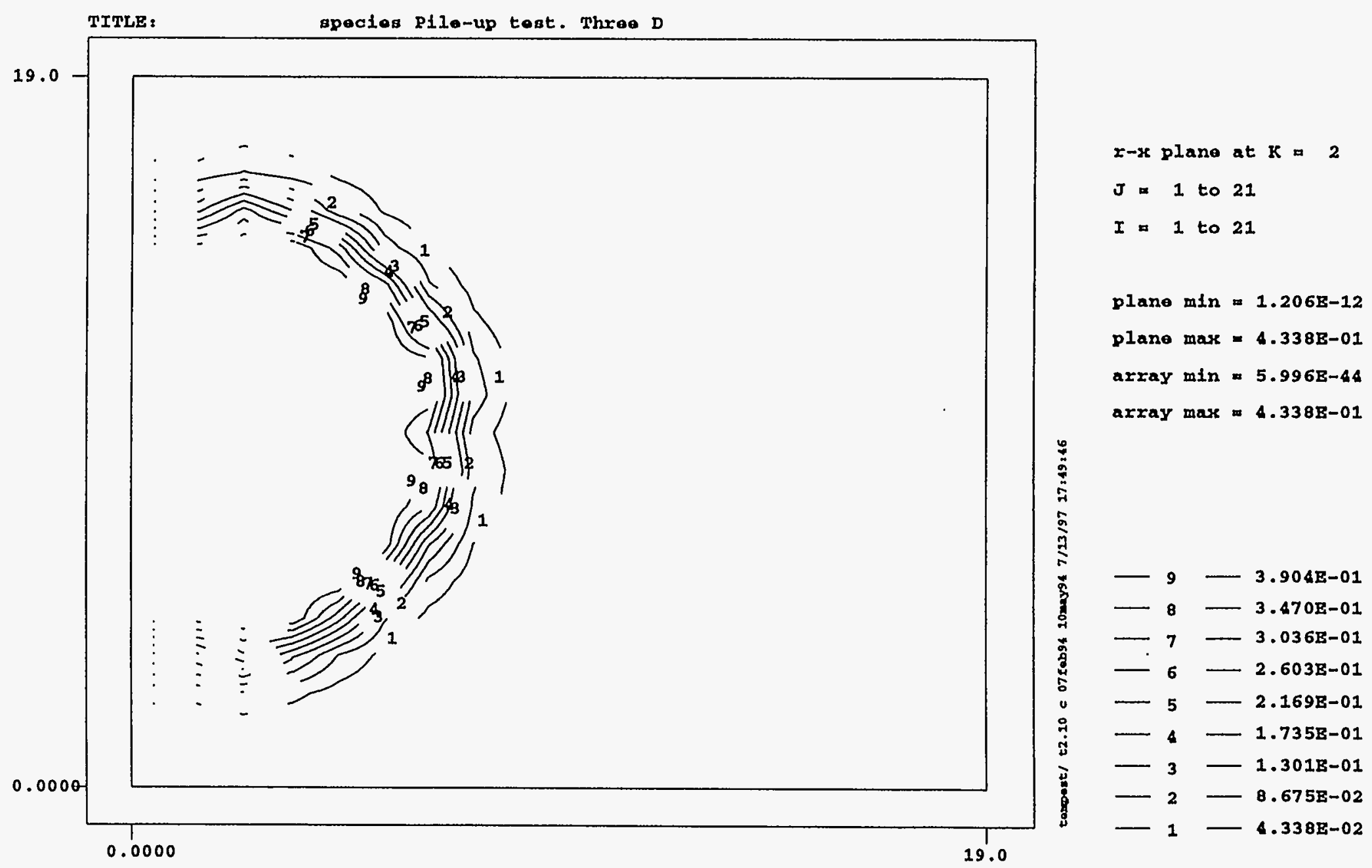

Figure 4.4. Predicted Sludge Accumulation Pattern (shown in solid volume fraction) on the Tank Bottom at 1 Hour and 23 Simulation Minutes 
plot at time = 1.389 houxs

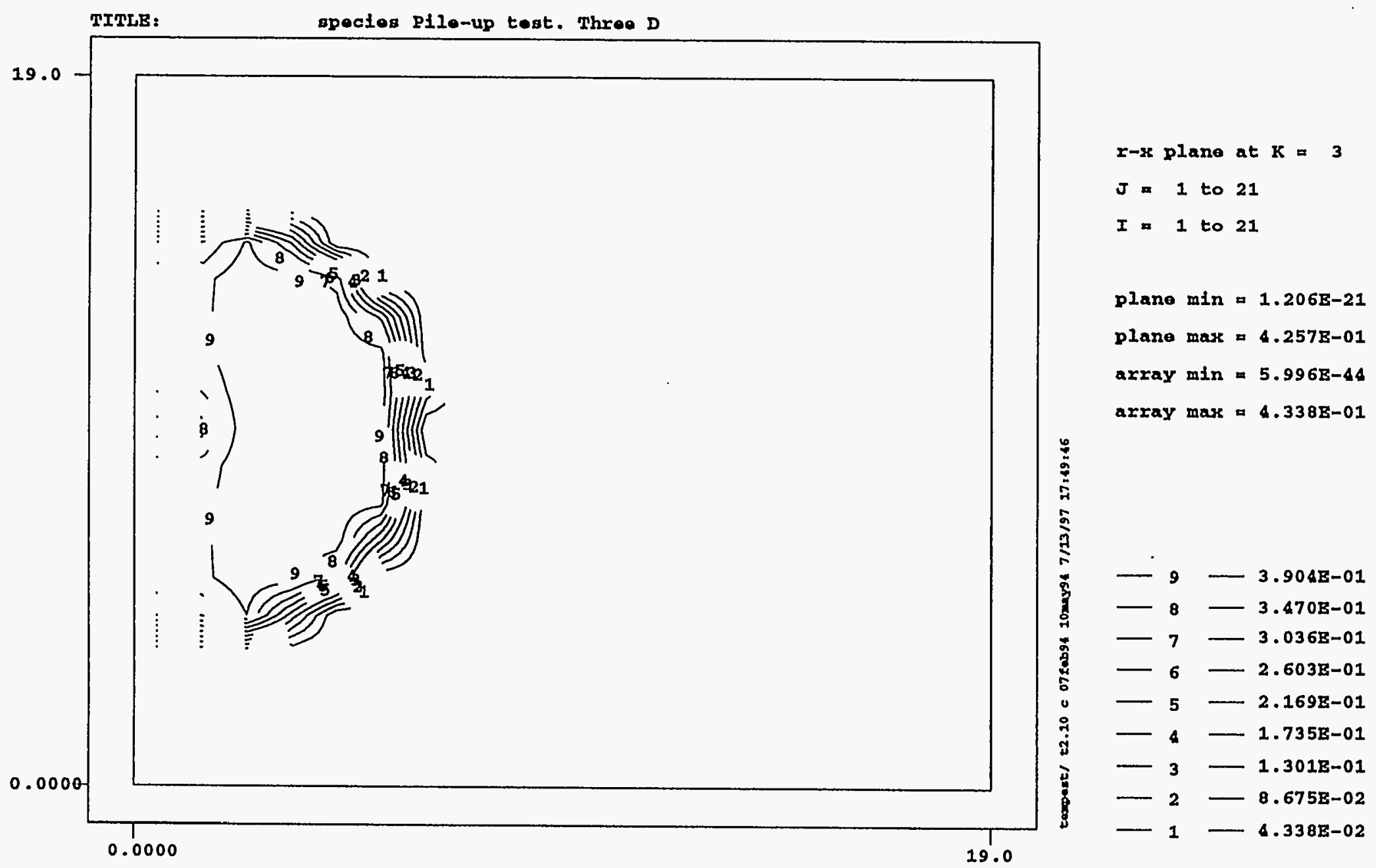

Figure 4.5. Predicted Sludge Accumulation Pattern (shown in solid volume fraction) $1 \mathrm{ft}$ above the Tank Bottom at 1 Hour and 23 Simulation Minutes 


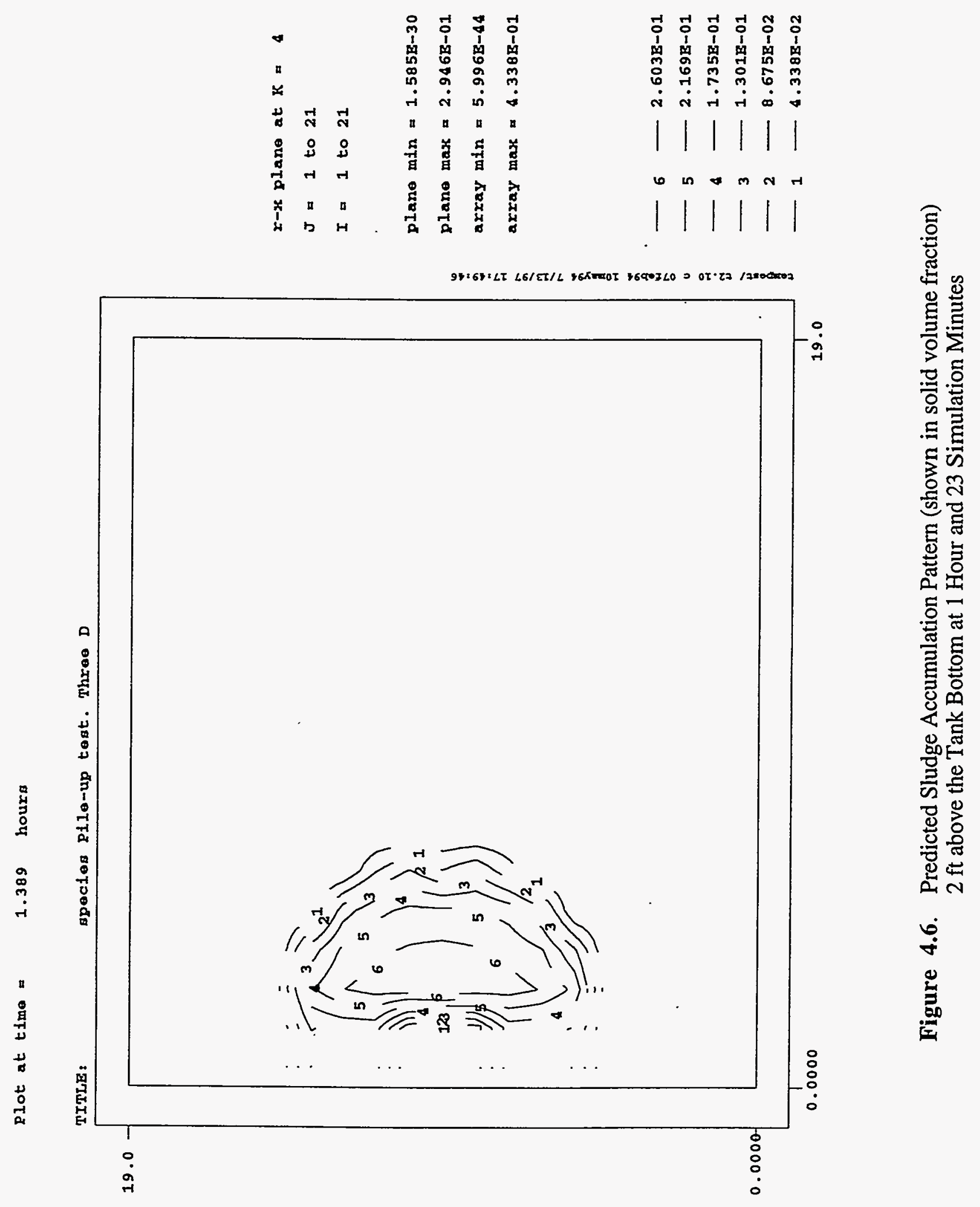




\subsection{Test Case 2: Diluent Jet Injection into Tank Sludge}

This test case simulated a liquid diluent being injected into and a supernatant liquid being withdrawn from a 19-ft-long $\times 20$-ft wide $\times 22$-ft-high rectangular tank. The diluent and supernatant density of $91 \mathrm{lb}_{\mathrm{m}} / \mathrm{ft}^{3}\left(1,460 \mathrm{~kg} / \mathrm{m}^{3}\right)$ and viscosity of $0.016 \mathrm{lb}_{\mathrm{m}} / \mathrm{ft}-\mathrm{sec}(24 \mathrm{cP})$ are the same as those assumed for Test Case 1.

This tank contains a layer of sludge 15 -ft-long, 20 -ft-wide and 8-ft-high with a 42 vol\% solids content. Supernatant liquid fills the rest of the tank. Solid density is assumed to be $136 \mathrm{lb}_{\mathrm{m}} / \mathrm{ft}^{3}\left(2,180 \mathrm{~kg} / \mathrm{m}^{3}\right)$, and the unhindered particle settling velocity was assigned to be $0.01 \mathrm{ft} / \mathrm{sec}(0.003 \mathrm{~m} / \mathrm{s})$. As in Test Case 1 , the computed solids settling velocity in the tank changes with the solid concentration because of the solid's hindering effect (see Equation 4.1).

The $4 \times$ 4-in. rectangular injection nozzle is located $4 \mathrm{ft}$ above the tank bottom along the tank lateral center. The diluent jet velocity at the nozzle exit was assigned to be $60 \mathrm{ft} / \mathrm{sec}(18.3 \mathrm{~m} / \mathrm{s})$ for this case. A withdrawal pump with its 4-in.-wide $\times 2.5$-ft-high opening is located $13 \mathrm{ft}$ above the injection nozzle ( $17 \mathrm{ft}$ above the tank bottom and $5 \mathrm{ft}$ below the supernatant surface) to remove the tank supernatant liquid at the same rate as the diluent is injected. When the flow shear stress acting on the sludge becomes greater than the sludge's yield strength, the sludge will be eroded, as discussed in Section 3. The sludge yield strength is calculated by Equation 3.6, assuming that the sludge's zero-strain yield strength is $1.5 \mathrm{psi}(10,000 \mathrm{~Pa})$ at $46 \mathrm{vol} \%$.

In the beginning of the test, the $60-\mathrm{ft} / \mathrm{sec}$ diluent jet impinges on the sludge bank immediately in front of the injection nozzle, as shown in Figure 4.7. Immediately after the initiation of the jet injection, the diluent is burrowing into the once immobile layer and diluting the original sludge, as shown in Figures 4.8 and 4.9 (at one simulation second). Figure 4.8 shows the predicted vertical distributions of flow and the solid volume fraction along the tank centerline, while Figure 4.9 illustrates their horizontal distribution $4 \mathrm{ft}$ above the tank bottom (the jet injection height). A three-dimensional representation (of a half tank cut along the jet centerline plane) at this simulation time is shown in Figure 4.10, clearly indicating the jet penetrating into the sludge layer.

As the jet penetrates and erodes the sludge, the buoyant jet flow spreads upward around the end of the penetration area. This upward moving flow dilutes the sludge above the jet in this area, as shown in Figure 4.11 (at two simulation seconds). This causes the sludge above the jet to collapse and produces very rapid mixing with the diluent and supernatant, as clearly shown in Figure 4.12 (at 20 simulation seconds). A comparison of predicted results at 15 simulation minutes and one simulation hour (Figure 4.13) shows only minor differences in the jet flow and sludge patterns. Thus, by 15 simulation minutes, the sludge that could be eroded was mostly eroded away. Figure 4.13 illustrates the extent that sludge will be mobilized by the $60-\mathrm{ft} / \mathrm{sec}$ jet injection for the conditions assumed. Test Case 2 demonstrated TEMPEST's ability to simulate both the mobility and the immobility of an erosion-resisting sludge layer. 
TITLE: TANR species exosion-resistance test. Three D Cartesian Grid

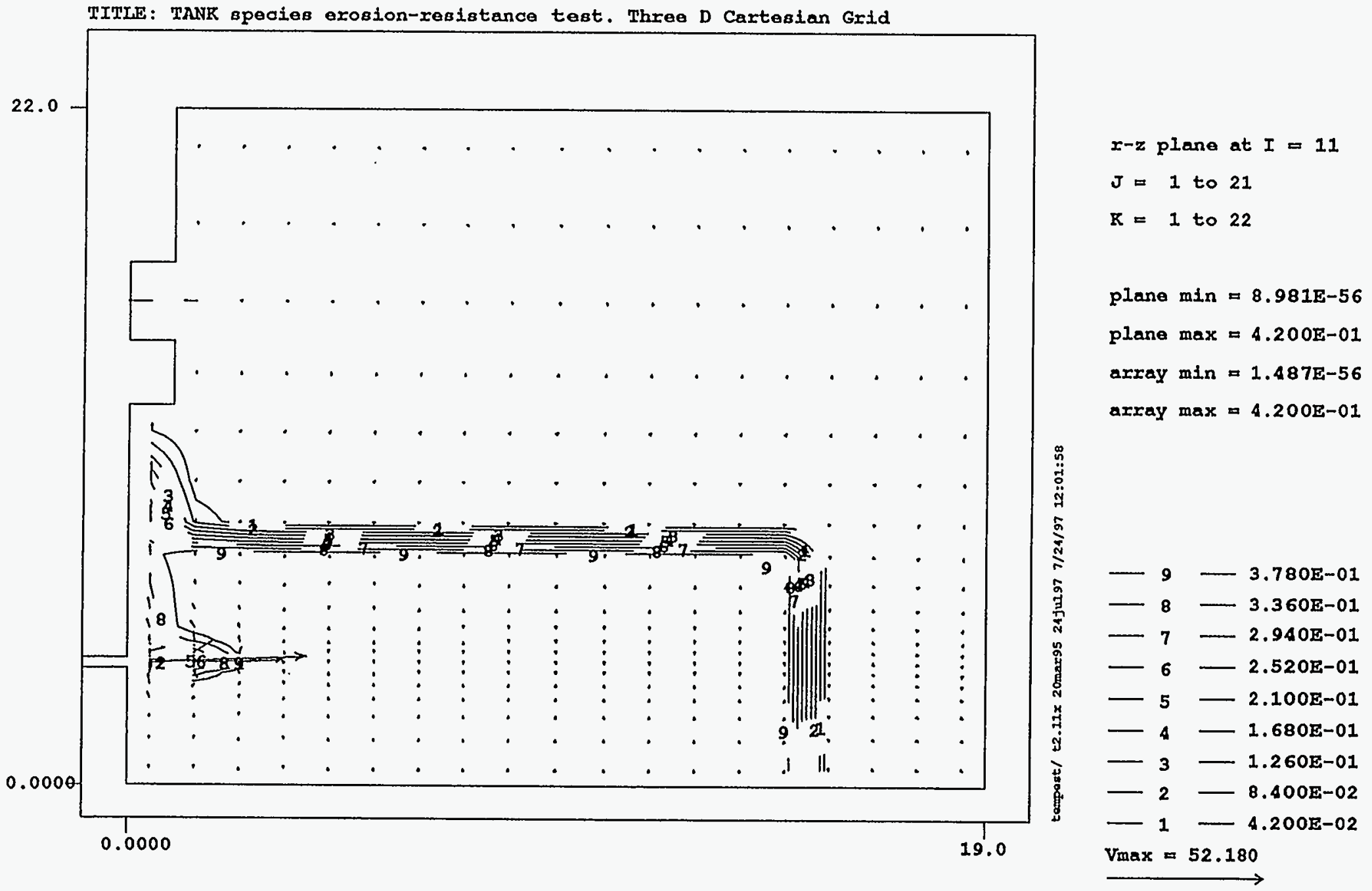

Figure 4.7. Diluent Injection and Supernate Withdrawal in a 19-ft-Long $\times 20$-ft-Wide $\times 22$-ft-High Rectangular Tank with Erosion-Resisting Sludge 
TITIE: TANK species exosion-resistance test. Three D Cartesian Grid

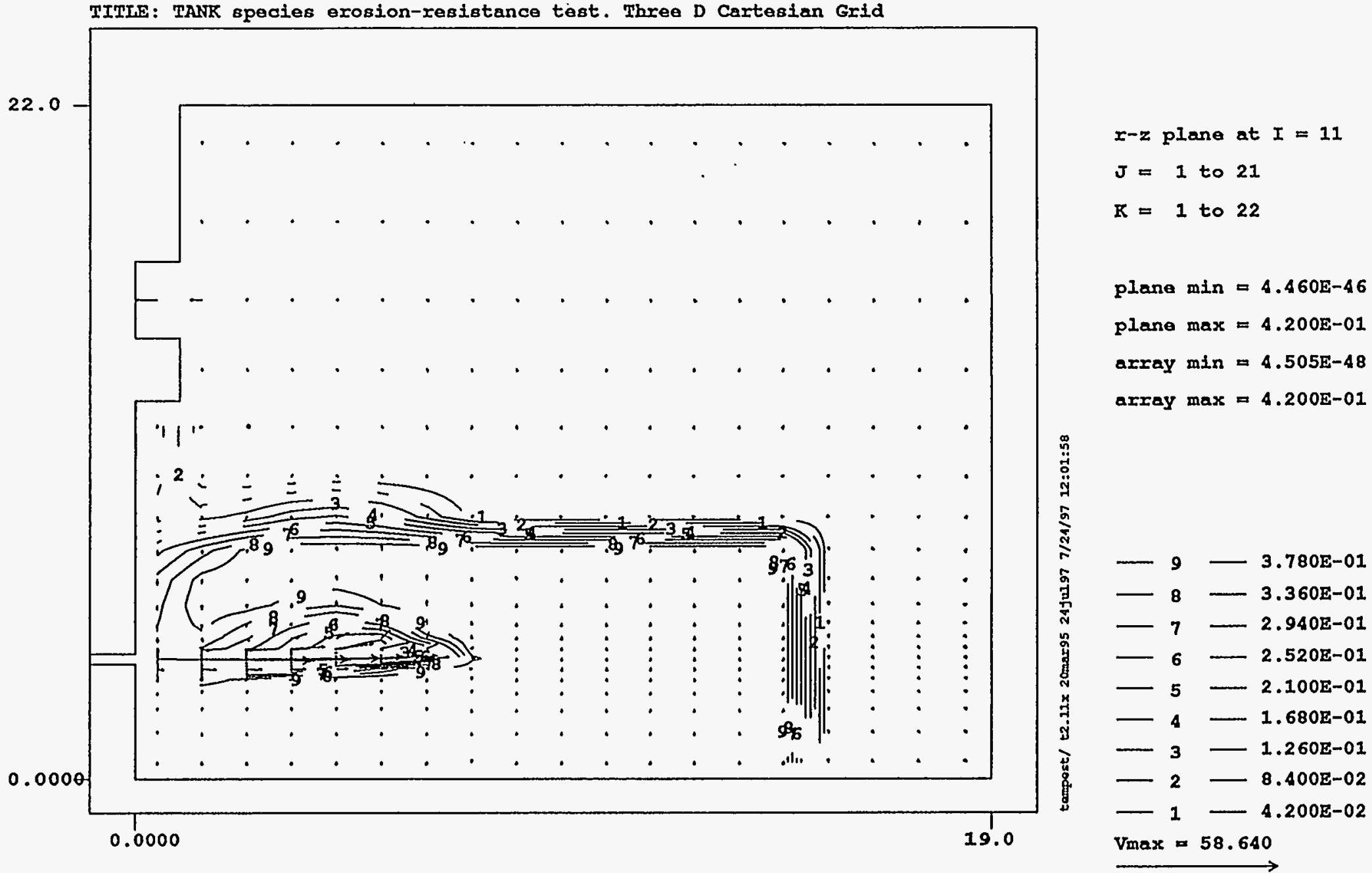

Figure 4.8. Predicted Jet Penetration into the Sludge (vertical distributions of flow velocity in $\mathrm{ft} / \mathrm{sec}$ and solid volume fraction) along the Tank Center at 1 Simulation Second 
Plot at time $=\quad 1.000$ seconds

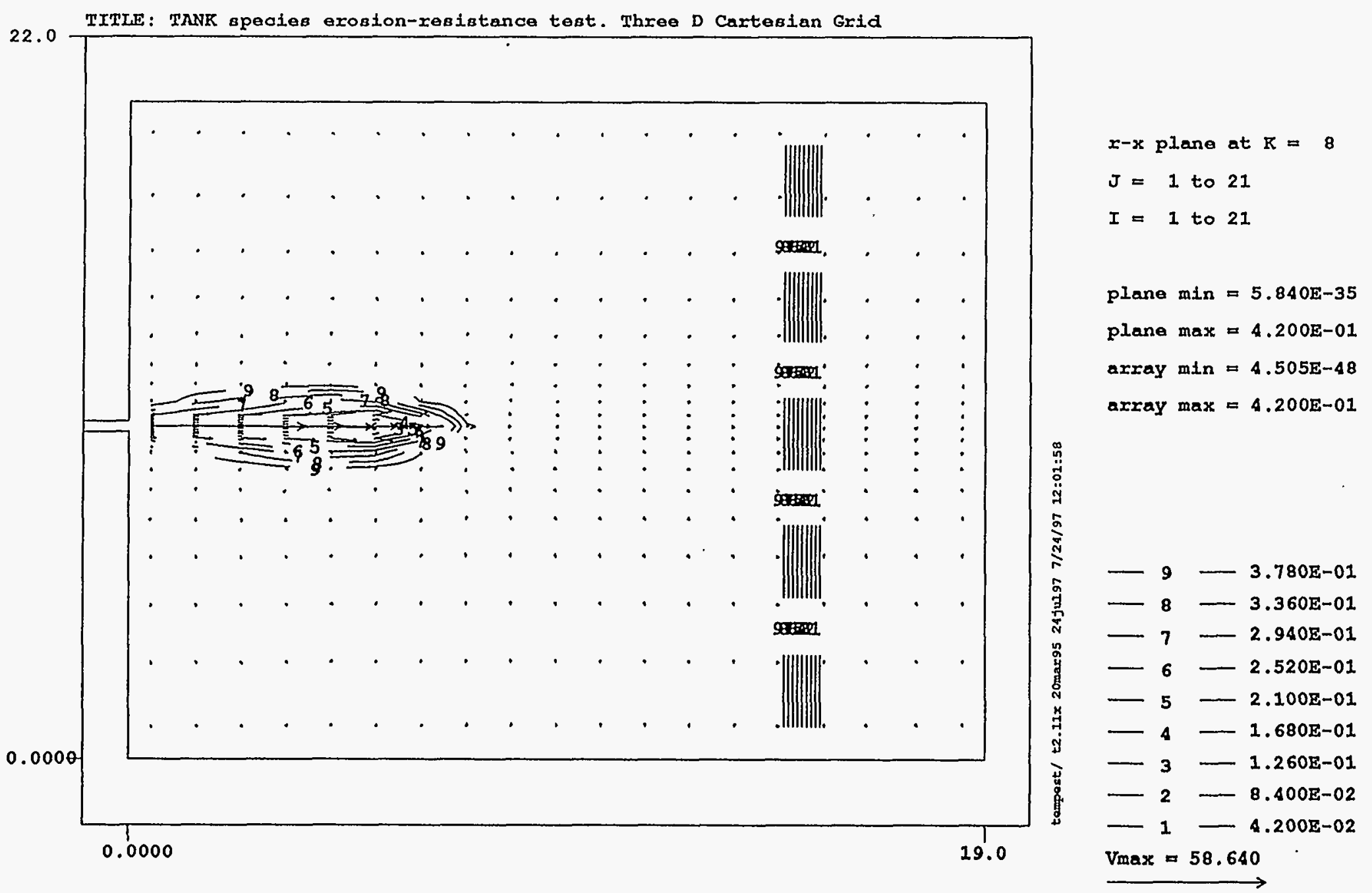

Figure 4.9. Predicted Velocity (ft/sec) and Horizontal Sludge Erosion Pattern (shown in solid volume fraction) $4 \mathrm{ft}$ above the Tank Bottom (diluent injection height) at 1 Simulation Second 


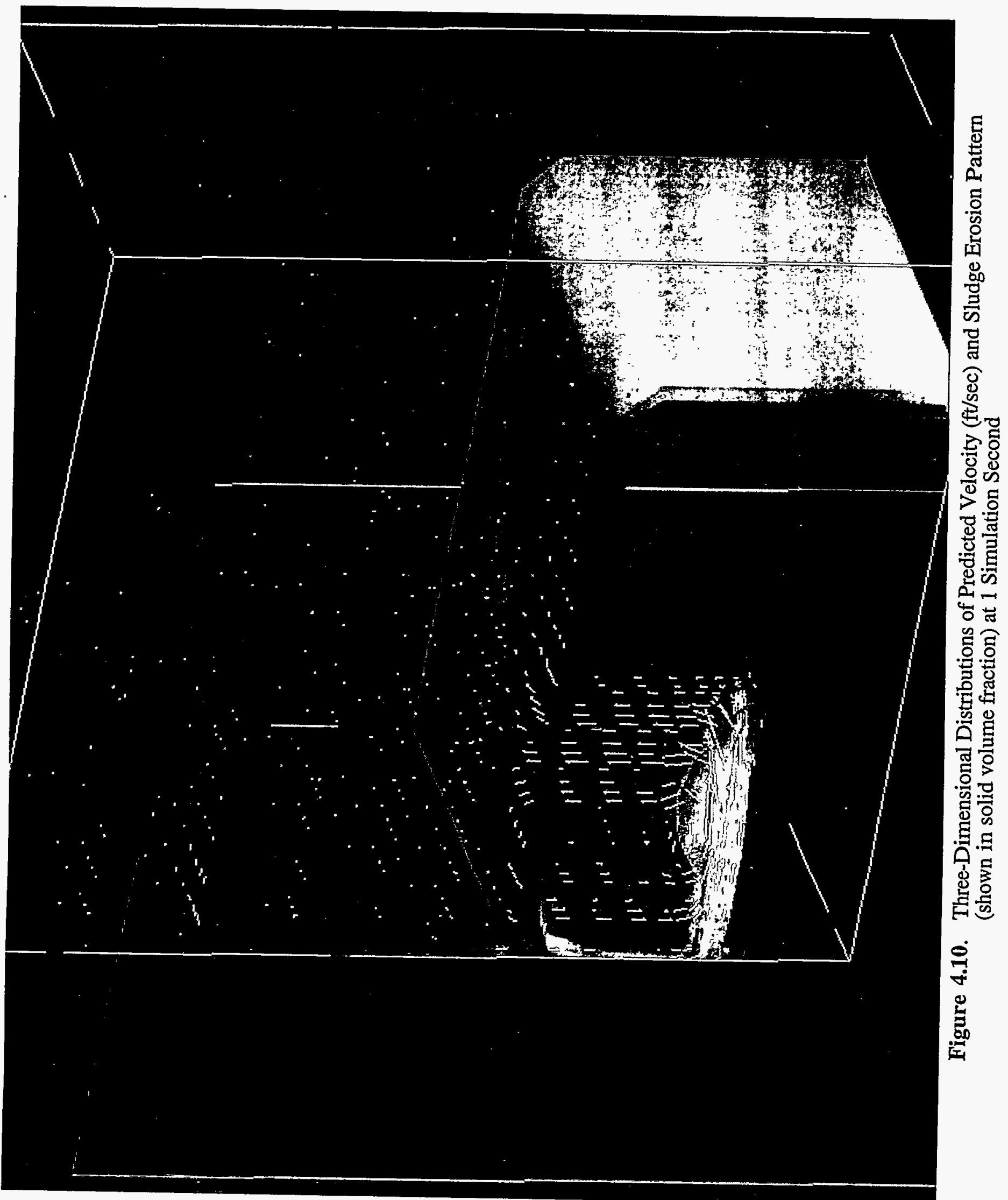




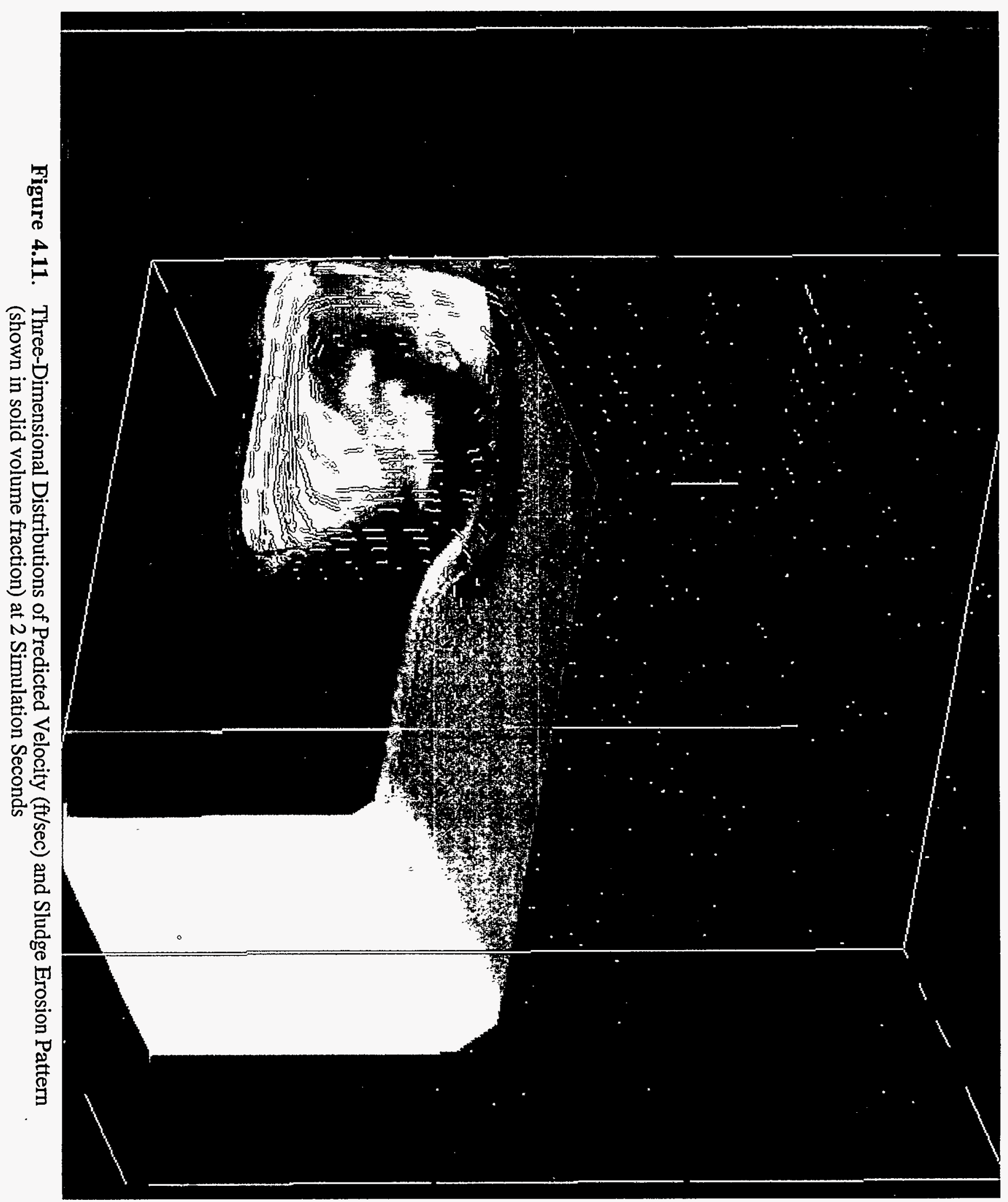




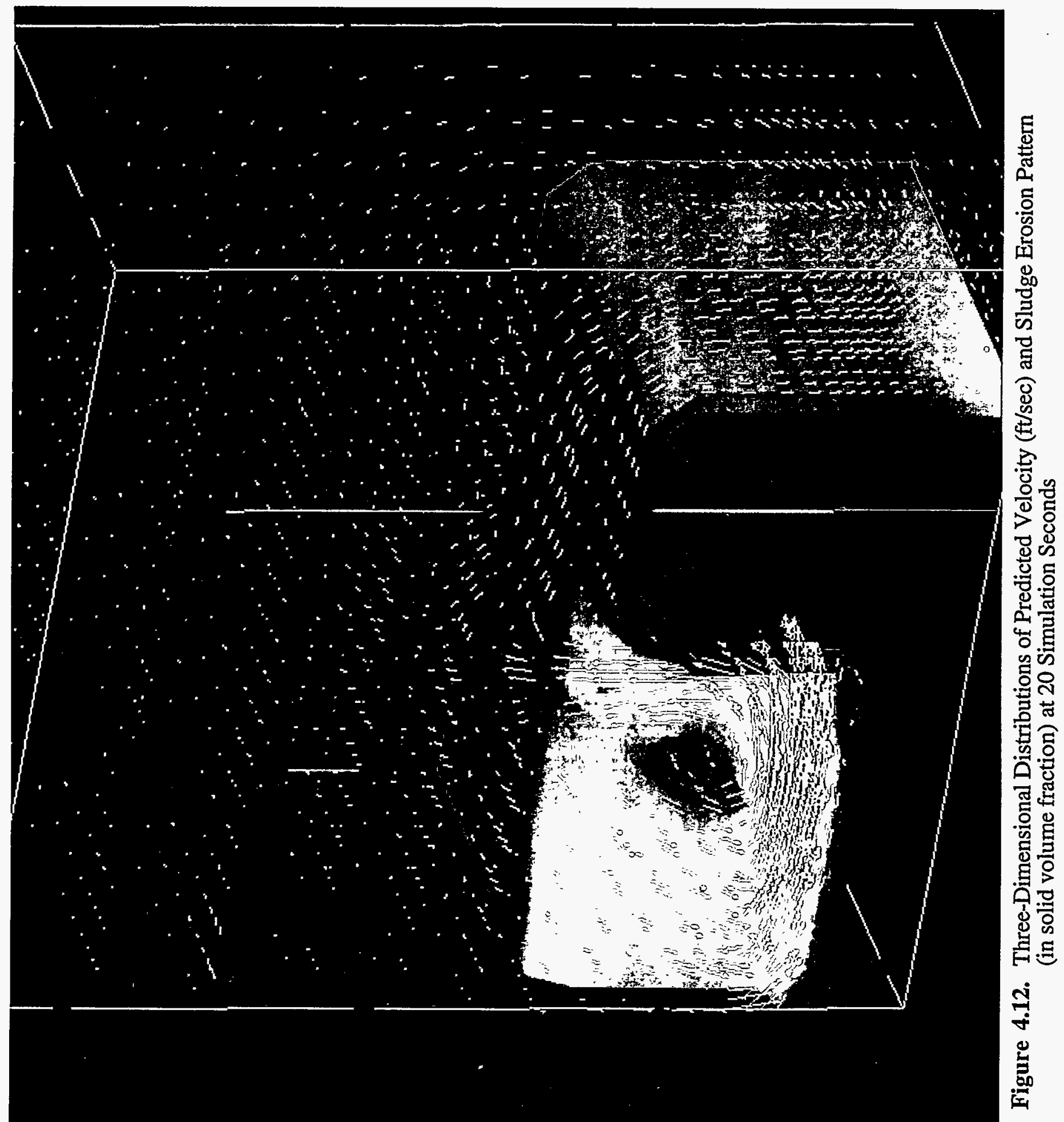




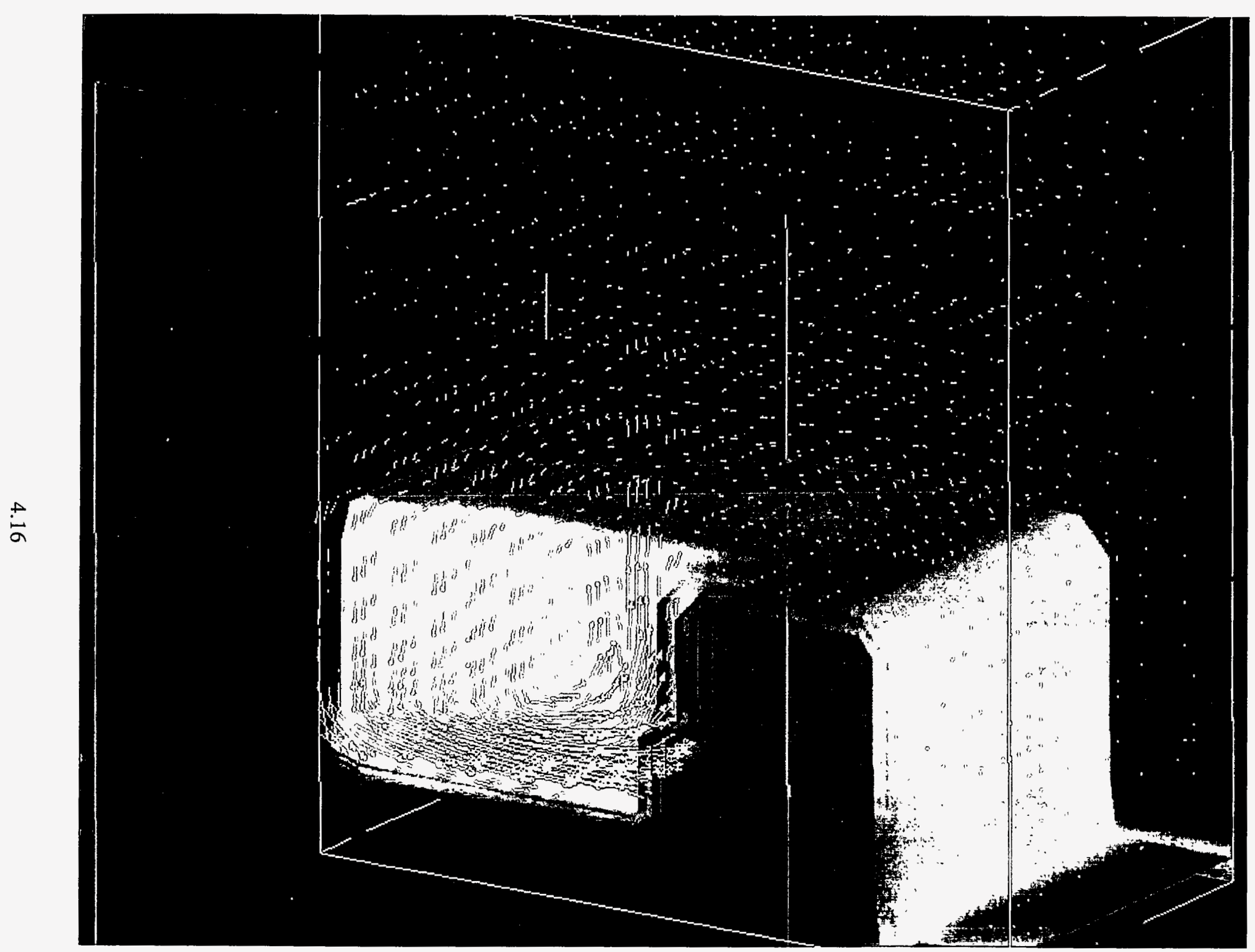

Figure 4.13. Three-Dimensional Distributions of Predicted Velocity ( $\mathrm{ft} / \mathrm{sec}$ ) and Sludge Erosion Patterns (in solid volume fraction) at 1 Simulation Hour 


\subsection{Test Case 3: Sludge Pump Jet Mixing}

The third test case presented is the simulated sludge pump jet mixing. In this case, the sludge pump withdraws the material near the bottom of the 19-ft long $x 20$-ft wide $\times 22-\mathrm{ft}$ high rectangular tank and injects it back into the tank. A $4 \times 4$-in. rectangular pump injection nozzle is located $4 \mathrm{ft}$ above the tank bottom along the tank lateral centerline. The pump withdrawal inlet is located $3 \mathrm{ft}$ above the bottom, as shown in Figure 4.14. The pump injection velocity is $60 \mathrm{ft} / \mathrm{sec}$.

The tank contains a sludge layer 15-ft-long, 20-ft-wide and 8-ft high composed of two solid volume fractions, as shown in Figure 4.14. One type of sludge surrounds the pump and has $22 \mathrm{vol} \%$ of solids, perhaps representing some dilution by a liquid injection before the start of the pump jet mixing operation. The rest of the sludge contains $42 \mathrm{vol} \%$ solids. The solids density was again assumed to be $136 \mathrm{lb}_{\mathrm{m}} / \mathrm{ft}^{3}\left(2,180 \mathrm{~kg} / \mathrm{m}^{3}\right)$. The sludge yield strength was internally calculated by Equation 2.29 , assuming the zero-strain yield strength, $\tau_{0}$, to be $1.5 \mathrm{psi}(10,000 \mathrm{~Pa})$ for 46 vol\% solids. The unhindered settling velocity of the solid particles was assigned to be $0.01 \mathrm{ft} / \mathrm{sec}(0.003 \mathrm{~m} / \mathrm{s})$, and hindered settling velocity was internally computed by TEMPEST, as in Test Case 2. The tank supernatant liquid, which fills the remainder of the tank, has a density of $91 \mathrm{lb}_{\mathrm{m}} / \mathrm{ft}^{3}\left(1,460 \mathrm{~kg} / \mathrm{m}^{3}\right)$ and a viscosity of $0.016 \mathrm{lb}_{\mathrm{m}} / \mathrm{ft}-\mathrm{sec}(24 \mathrm{cP})$, the same as in the previous two cases.

The $60-\mathrm{ft} / \mathrm{sec}$ slurry jet quickly burrows into both the 22- and 42 -vol\% sludges in front of the injection nozzle, as shown in Figure 4.15 (at one simulation second). However, as shown in Figure 4.16 (at one simulation second), the lateral extent of sludge erosion is rather limited. As the pump withdraws the slurry and injects it back into the sludge, the jet penetrates deeper into the sludge bank and dilutes the sludge above the jet extensively, as shown in Figure 4.17 (at five simulation seconds). By one simulation minute, a large portion of the original sludge in front of the pump injection nozzle has been mobilized by the recirculating slurry jet (see Figure 4.18). However, its lateral spread is still rather limited because the sludge resists being mobilized by the weaker jet-induced shear stress at the periphery of the jet, as shown in Figure 4.19 (one simulation minute). The horizontal sludge erosion pattern shows a small asymmetry; we are examining this aspect.

As indicated in Figures 4.20 ( 5 simulation minutes) and 4.21 ( 15 simulation minutes), after 5 and 15 minutes of pump operation the additional sludge erosion is mostly confined to small areas of the upper and sides of the jet, rather than the center. Thus these model results clearly reveal that some portion of the sludge is not expected to be eroded away even with longer pump operation. The lateral erosion of the sludge at 15 simulation minutes also supports this conclusion that some portions of the tank sludge will remain immobilized in this hypothetical pump jet operation. This indicates the benefit of using rotating jets to achieve much larger lateral sludge erosion. Test Case 3 thus demonstrates that TEMPEST is capable of simulating the erosion and immobilization of sludge for the pump jet operating conditions assumed. 
Flow and Solid Volume Fraction

plot at time

0.017 seconds

TITLE: TANK species orosion-resistance test. Throe $\mathrm{D}$ Cartesian Grda

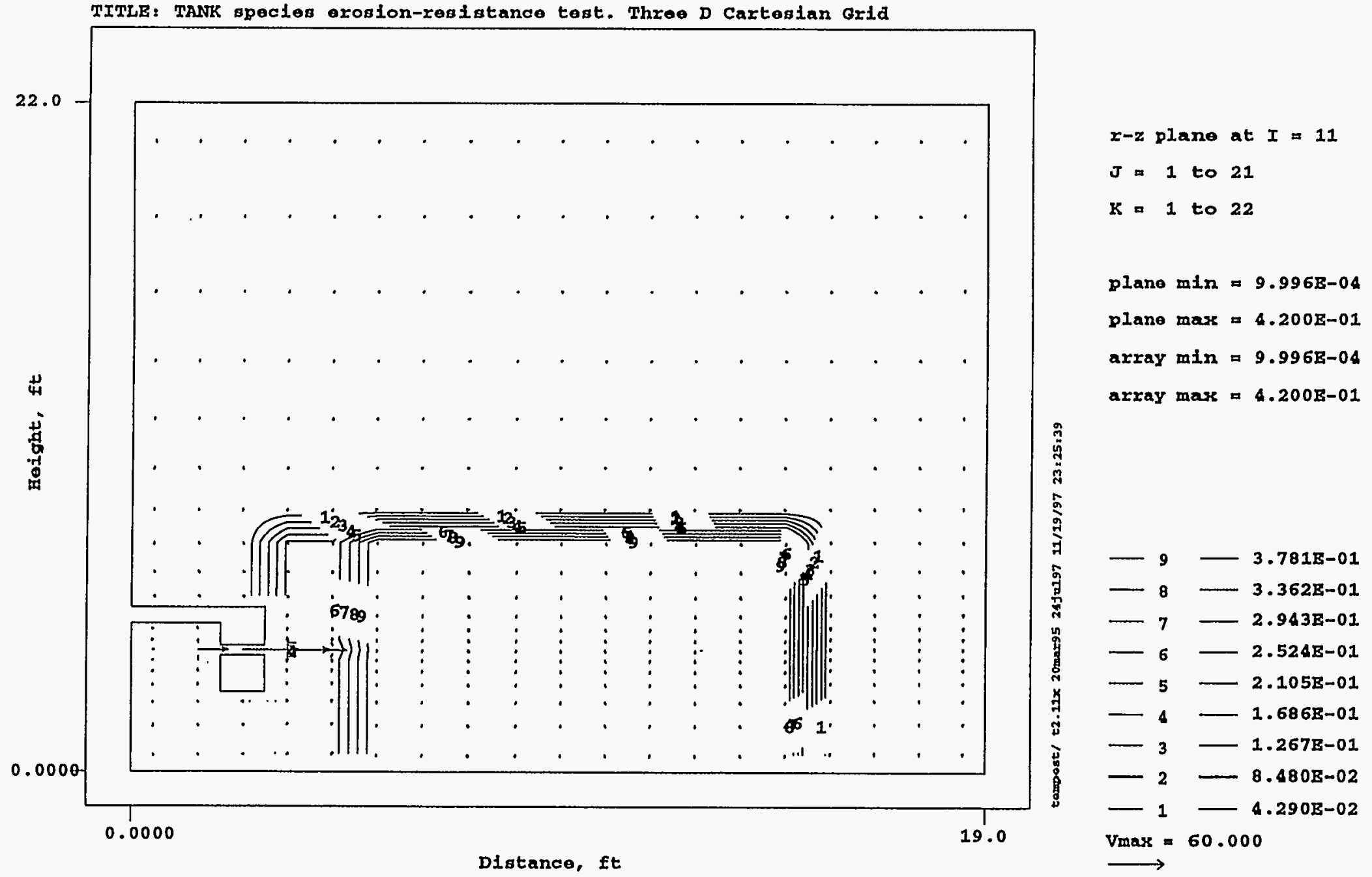

Figure 4.14. Pump Jet Mixing in a 19-ft-Long $x$ 20-ft-Wide $x$ 22-ft-High Rectangular Tank with Erosion-Resisting Sludge 
Flow and Solid Volume Fraction

Plot at time $=1.000$ seconds

TITLE: TANK spocios orosion-rosistance tost. Throe D Cartesian orid

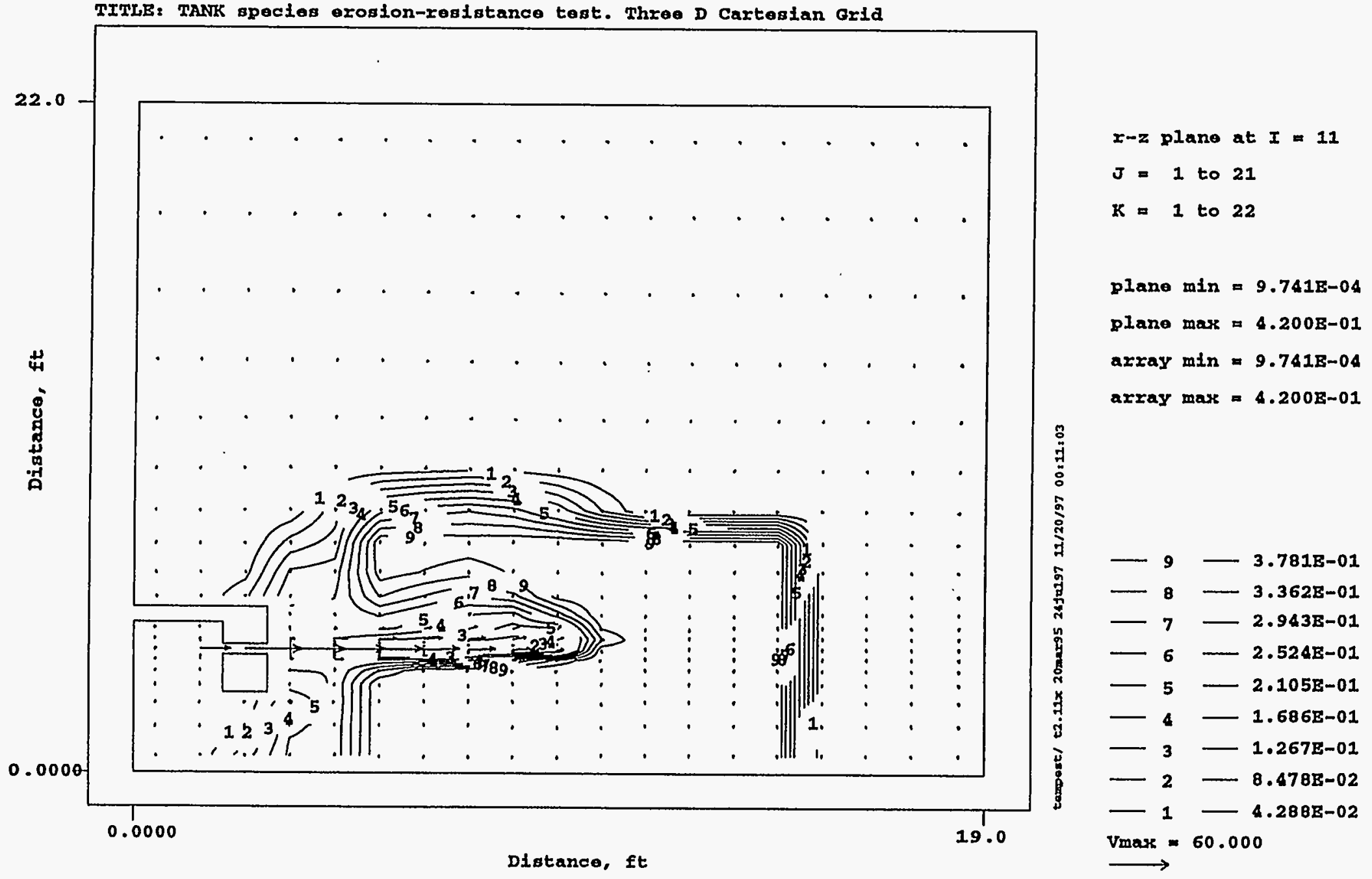

Figure 4.15. Predicted Jet Penetration into the Sludge (vertical distributions of flow velocity in $\mathrm{ft} / \mathrm{sec}$ and solid volume fraction) along the Tank Center at 1 Simulation Second 
Flow and Solid Volume Fraction

Plot at time 1.000 seconds

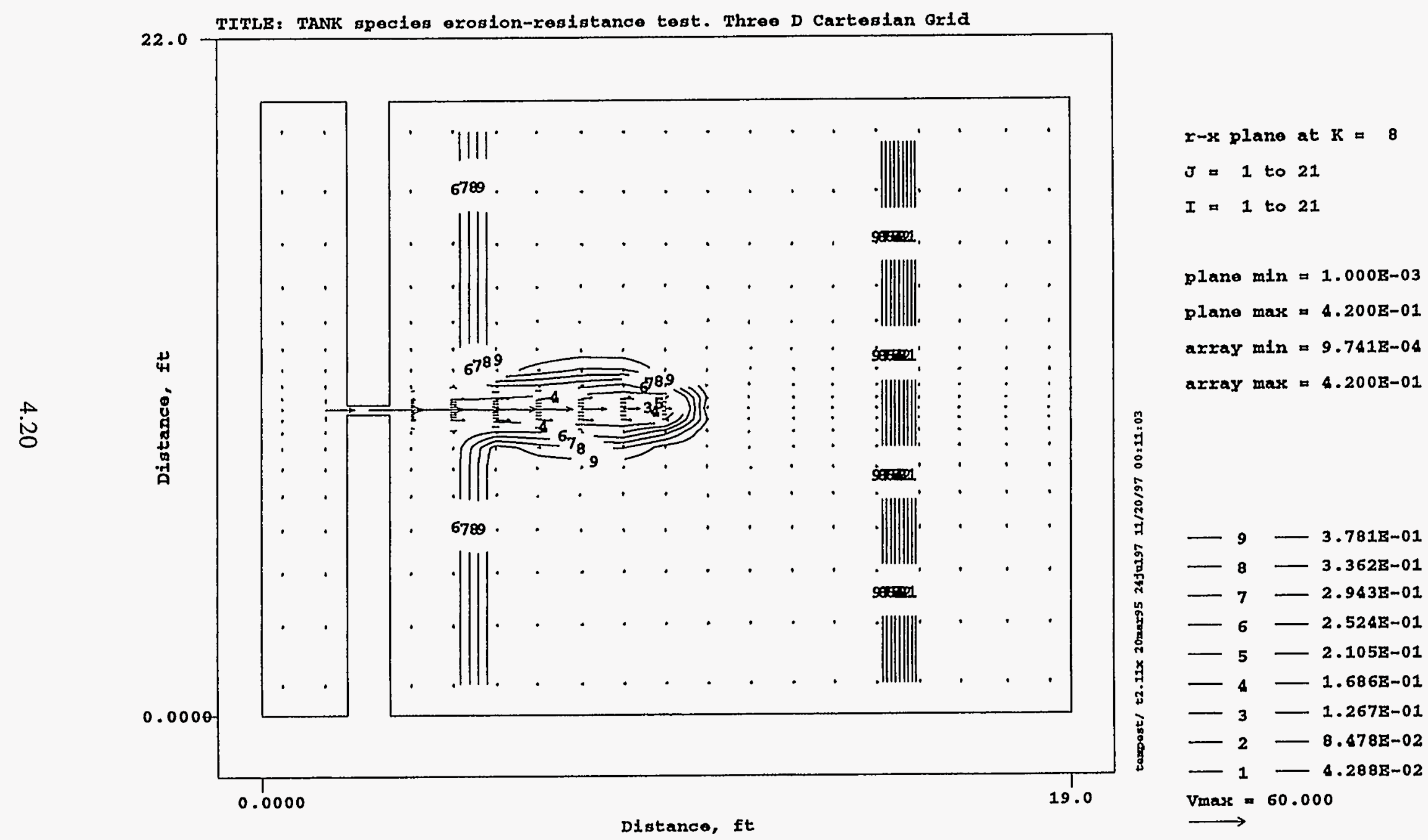

Figure 4.16. Predicted Velocity $(\mathrm{ft} / \mathrm{sec}$ ) and Horizontal Sludge Erosion Pattern (shown in solid volume fraction) $4 \mathrm{ft}$ above the Tank Bottom (pump jet injection height) at 1 Simulation Second 
Flow and Solid Volume Fraction

Plot at time $=5.000$ seconds

TITLE: TANK species erosion-resistance test. Threo D Cartesian Crid

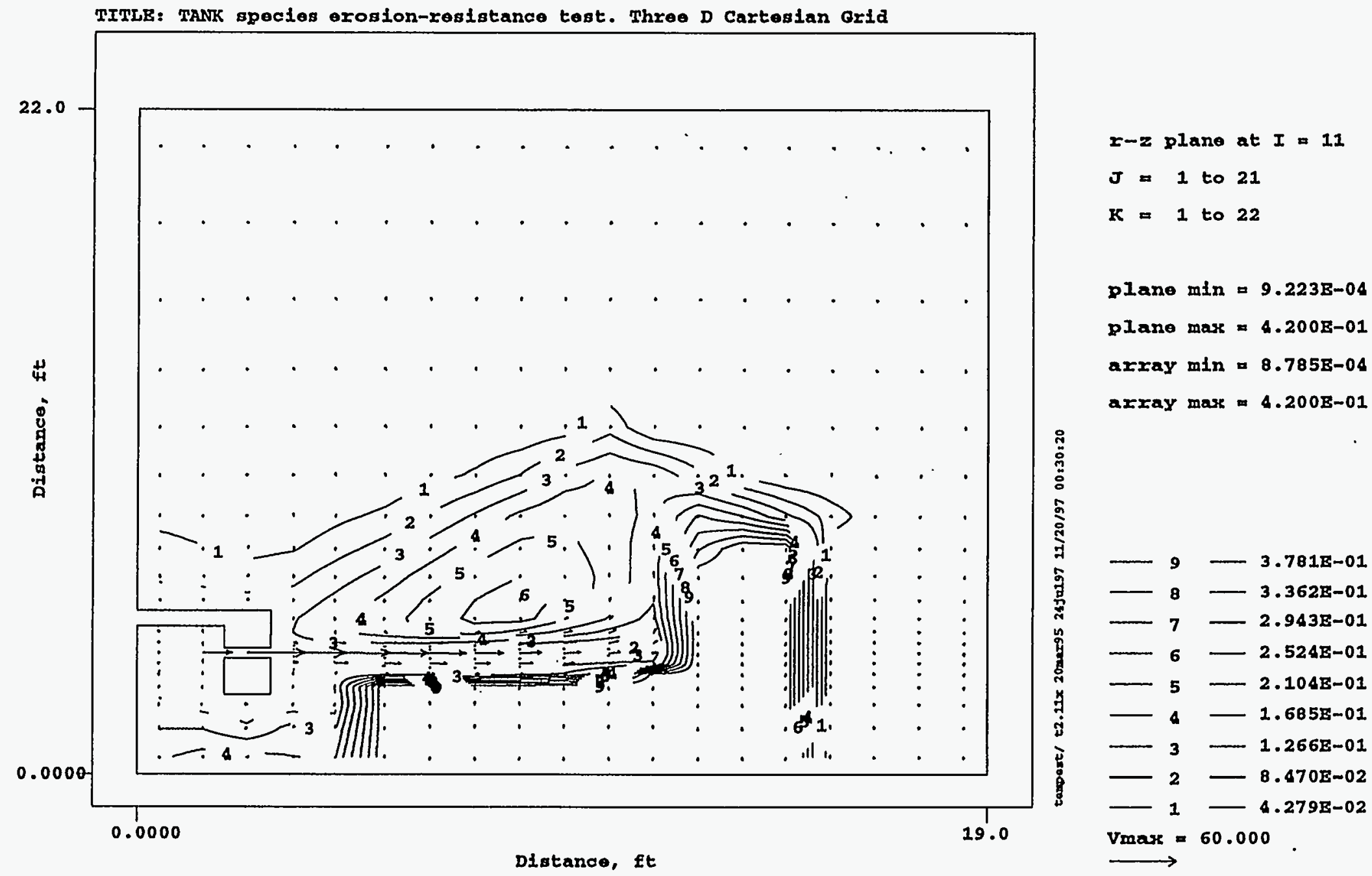

Figure 4.17. Predicted Jet Penetration into the Sludge (vertical distributions of flow velocity in $\mathrm{ft} / \mathrm{sec}$ and solid volume fraction) along the Tank Center at 5 Simulation Seconds 
Flow and Solid Volume Fraction

Plot at time $=60.000$ seconds

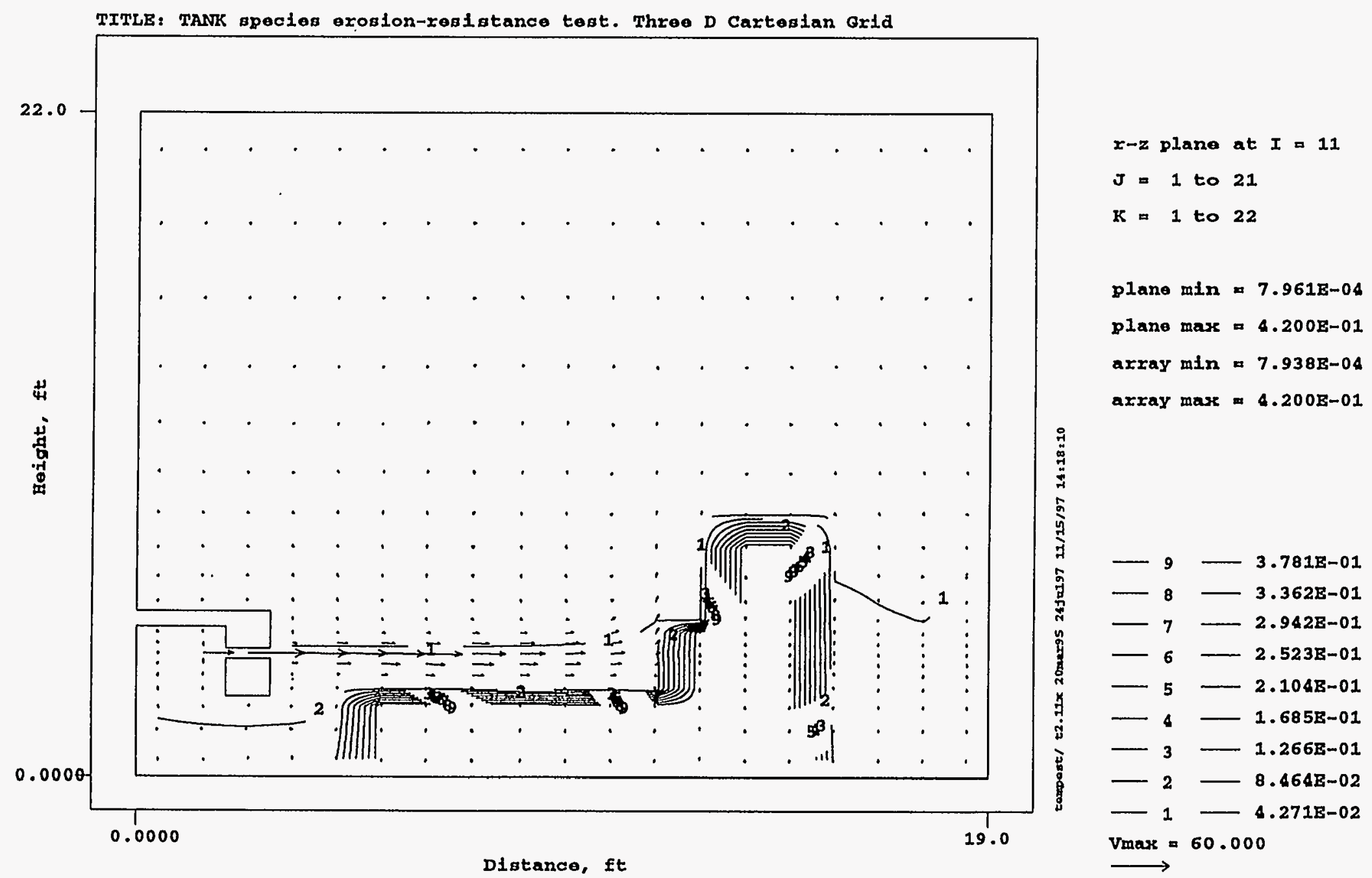

Figure 4.18. Predicted Jet Penetration into the Sludge (vertical distributions of flow velocity in $\mathrm{ft} / \mathrm{sec}$ and solid volume fraction) along the Tank Center at 1 Simulation Minute 
Flow and Solid Volume Fraction

Plot at time $=\quad 60.000$ seconds

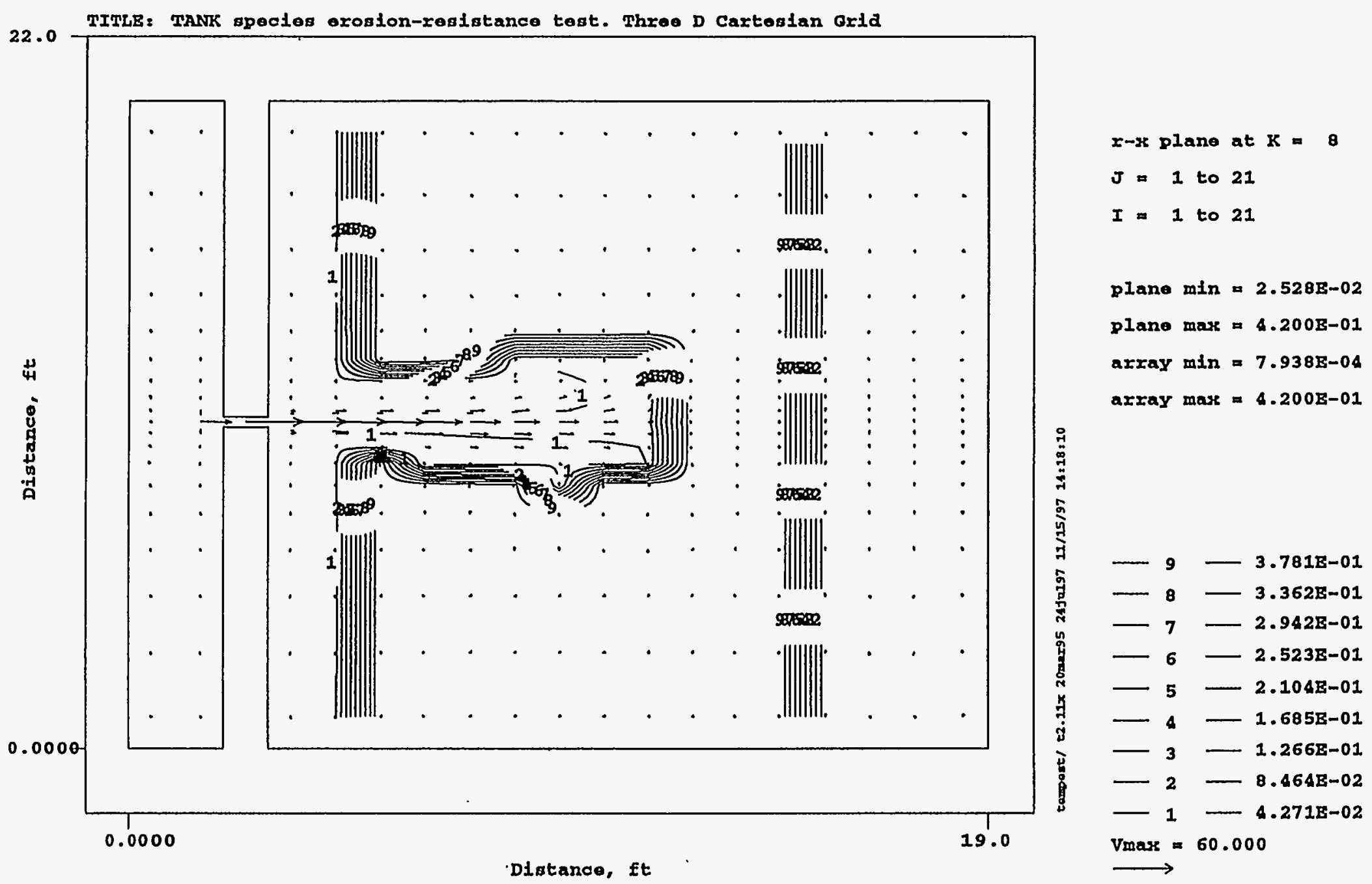

Figure 4.19. Predicted Velocity (ft/sec) and Horizontal Sludge Erosion Pattern (shown in solid volume fraction) $4 \mathrm{ft}$ above the Tank Bottom (pump jet injection height) at 1 Simulation Minute 


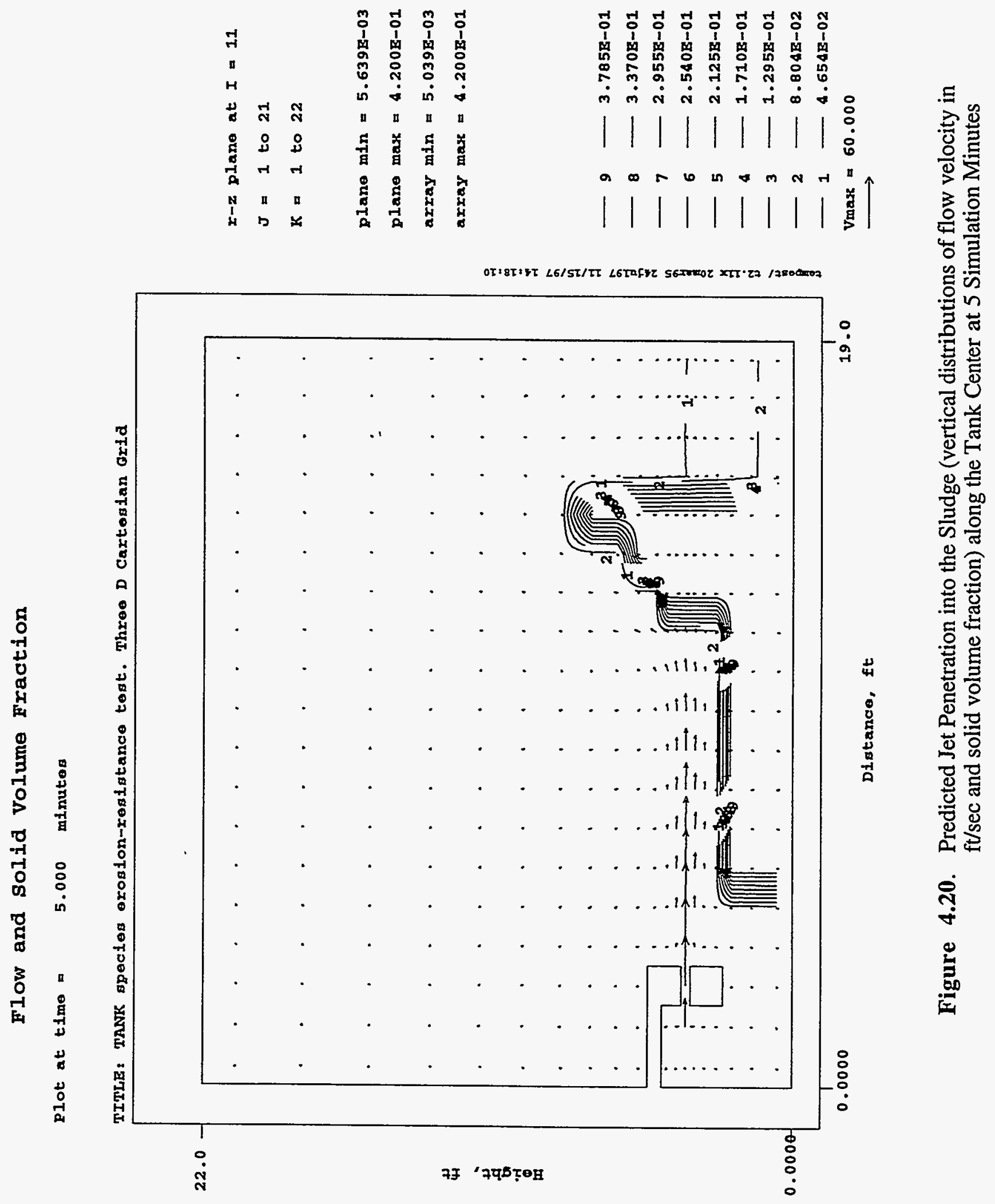


Flow and Solid Volume Fraction

Plot at time $=" 15.000$ minutes

TITLE: TANK spocios orosion-resistance tost. Three D Cartostan Grid

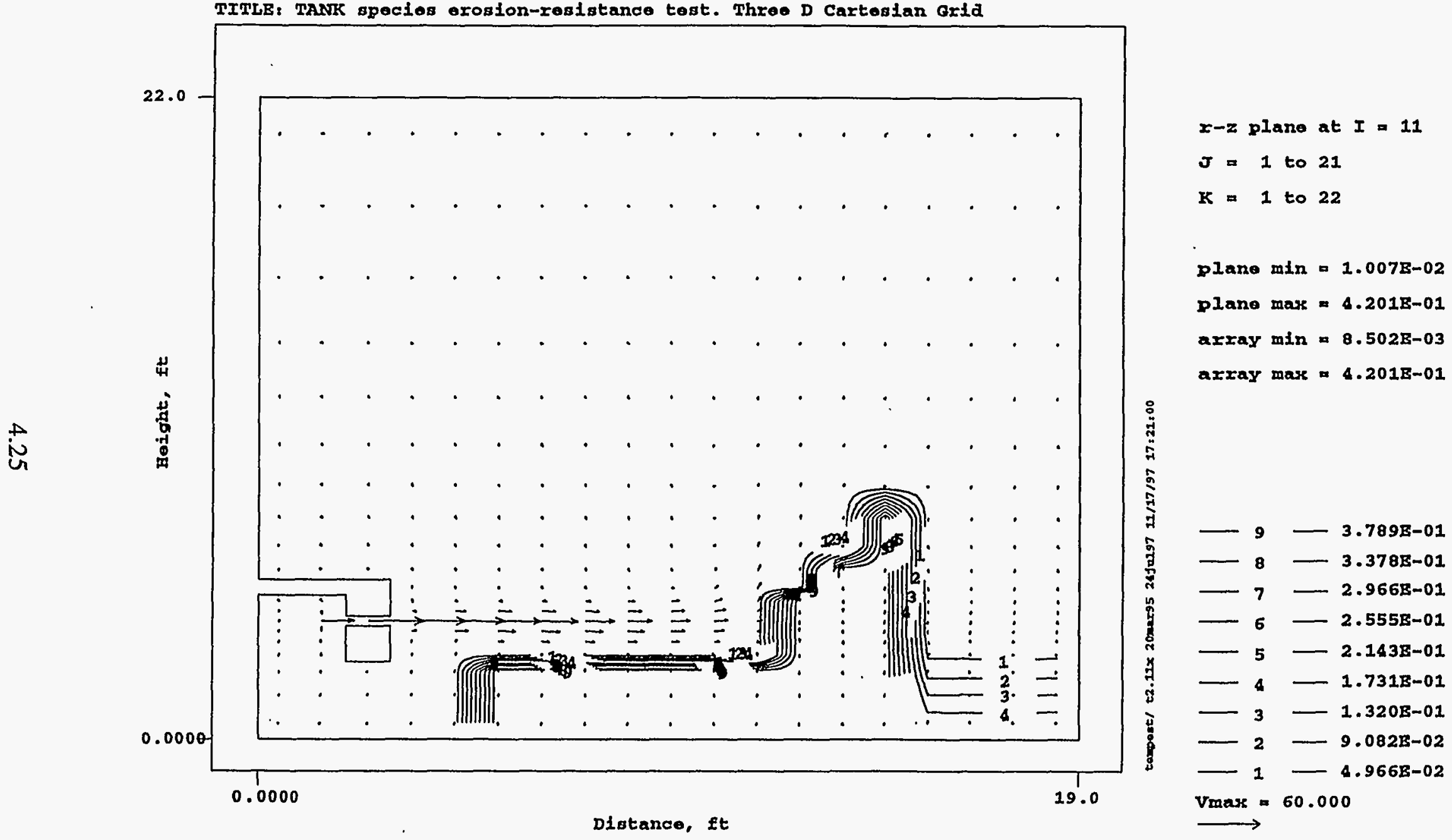

Figure 4.21. Predicted Velocity $(\mathrm{ft} / \mathrm{sec}$ ) and Sludge Erosion Pattern (shown in solid volume fraction) along the Tank Center at 15 Simulation Minutes 
Flow and Solid Volume Fraction

Plot at time $=\quad 15.000$ minuter

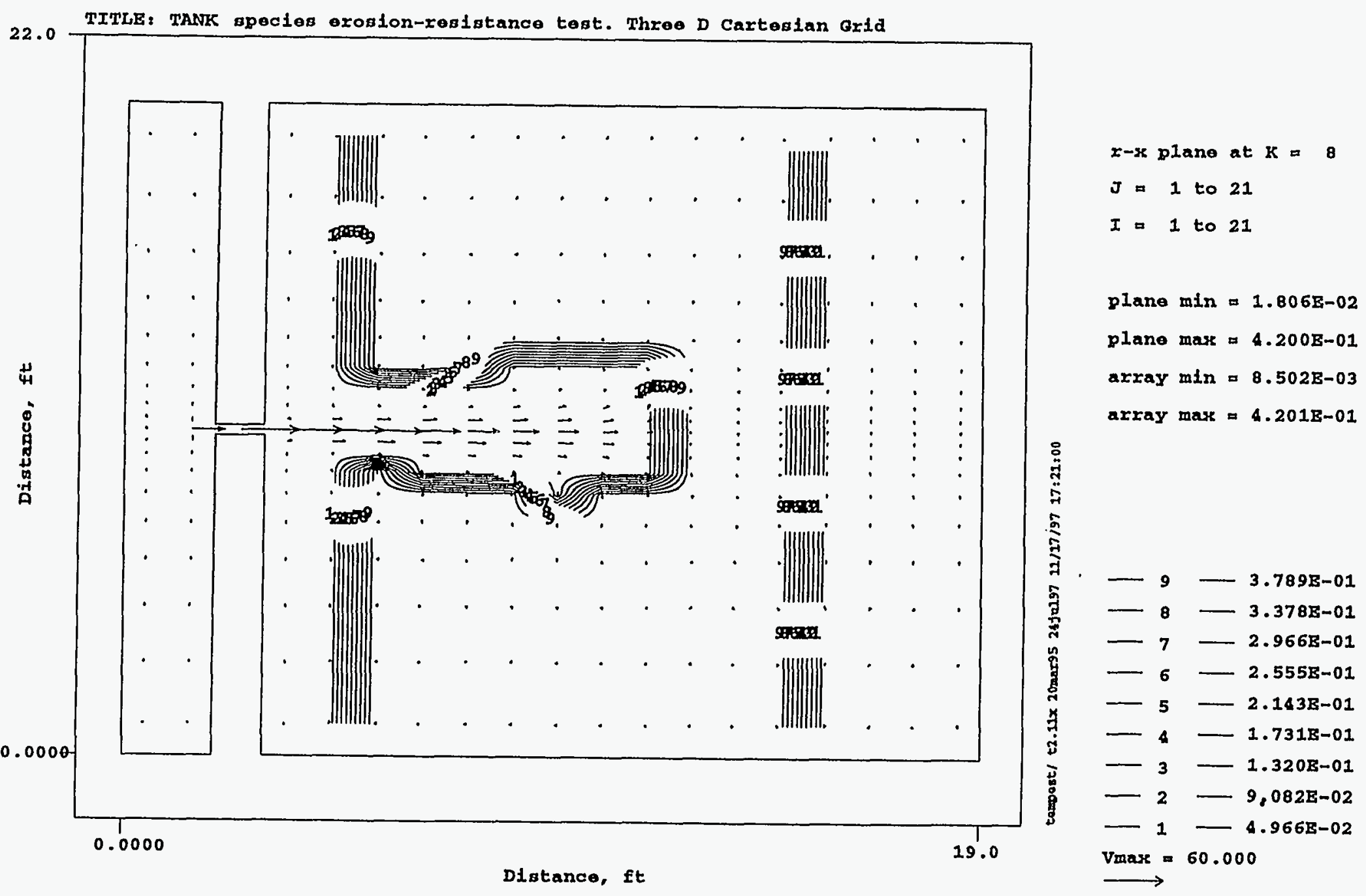

Figure 4.22. Predicted Velocity ( $\mathrm{ft} / \mathrm{sec}$ ) and Horizontal Sludge Erosion Pattern (shown in solid volume fraction) $4 \mathrm{ft}$ above Tank Bottom (pump jet injection height) at 15 Simulation Minutes 


\subsection{Summary and Conclusions}

Because the amount of sludge retrieved from the tank bottom is directly related to the yield strength of the sludge and shear stress acting on it, we modified the TEMPEST code to implement a new calculational procedure to simulate the effect of sludge yield strength on tank waste mobilization. The modified code was applied to simplified three-dimensional test cases for slurry deposition and diluent/slurry injection into the sludge layers.

The slurry deposition model test produced localized solid accumulation on the tank bottom that gained yield strength with aging. The test demonstrated that the TEMPEST model can simulate localized settled sludge pile-up and subsequent immobilization.

The test case of the $60-\mathrm{ft} / \mathrm{sec}$ diluent injection into the sludge indicated that, by 15 simulation minutes to one hour, the sludge that could be eroded was mostly eroded away, but some sludge would remain immobilized under the condition tested. The pump jet mixing test case also shows similar results. Since TEMPEST predicted that sludges without yield strength were eventually all mobilized by tank jet flows, the partial erosion predicted by the model is due to the erosion resisting yield strength of the sludge.

The three model tests presented show that our first cut at a sludge erosion model with yield strength is predicting mobilization of erosion-resisting sludge. Thus the TEMPEST code has the basic ability to simulate both mobility and immobility of the sludge with yield strength. We are planning for further testing, modification, calibration, and verification of the sludge mobilization/ immobilization model with erosion data applicable to waste tank sludges. 


\subsection{References}

Aagaard P and Helgeson. 1982. "Thermodynamic and Kinetic Constraints on Reaction Rates among Minerals and Aqueous Solution, I, Theoretical Considerations." American Journal of Science, Vol. 282, pp. 237-285.

Ellwood KR et al. 1990. "Laminar Jets of Bingham-Plastic Liquids." J. of Rheology, 34(6):787812.

Felmy AR. 1990. GMIN: A Computerized Chemical Equilibrium Model Using a Constrained Minimization of the Gibbs Free Energy. PNL-7281, Pacific Northwest National Laboratory, Richland, Washington.

Felmy AR. 1995. "GMIN: A Computerized Chemical Equilibrium Program Using a Constrained Minimization of the Gibbs Free Energy." Chemical Equilibrium and Reaction Models. SSSA Special Publication 42, pp. 31-52.

Harvie CE, JP Greenberg, and JH Weare. 1987. "A Chemical Equilibrium Algorithm for Highly Non-Ideal Multiphase Systems: Free Energy Minimization." Geochemica et Cosmochimica Acta, Vol. 51, pp. 1045-1057.

Jansen PPh, L van Bendegom, J van den Berg, $\mathrm{M}$ deVries, and A Zanen, eds. 1979. Principles of River Engineering-The Non-Tidal Alluvial River. Pitman Publishing Limited, London.

Mahoney LA and DS Trent. 1995. Correlation Models for Waste Tank Slidge and Slurries. PNL-10695, Pacific Northwest National Laboratory, Richland, Washington.

Meyer PA. 1994. Computer Modeling of Jet Mixing in INEL Waste Tanks. PNL-9063, Pacific Northwest Laboratory, Richland, Washington.

Onishi Y, HC Reid, and DS Trent. 1995. Dilution Physics Modeling: Dissolution/Precipitation Chemistry. PNL-10815, Pacific Northwest Laboratory, Richland, Washington.

Onishi Y, R Shekarriz, KP Recknagle, PA Smith, J Liu, YL Chen, DR Rector, and JD Hudson. 1996a. Tank SY-102 Waste Retrieval Assessment: Rheological Measurements and Pump Jet Mixing Simulation. PNNL-11352, Pacific Northwest National Laboratory, Richland, Washington.

Onishi Y, HC Reid, DS Trent, and JD Hudson. 1996b. "Tank Waste Modeling with Coupled Chemistry and Hydrothermal Dynamics." In Proceedings of 1996 National Heat Transfer Conference, American Nuclear Society, Houston, Vol. 9, pp. 262-269.

Onishi Y and KP Recknagle. 1997. Tank AZ-101 Criticality Assessment Resulting from Pump Jet Mixing: Sludge Mixing Simulations. PNNL-11486, Pacific Northwest National Laboratory, Richland, Washington.

Powell MR, Y Onishi, and A Shekarriz. 1997. Research on Jet Mixing of Settled Sludges in Nuclear Waste Tanks at Hanford and Other DOE Sites: A Historical Perspective. PNNL-11686, Pacific Northwest National Laboratory, Richland, Washington. 
Richardson JF and WN Zaki. 1954. "Sedimentation and Fluidisation: Part I." Trans. Instn. Chem. Engr., 32:35-53.

Snoeyink VL and D Jenkins. 1980. Water Chemistry. John Wiley and Sons, New York.

Steefel CL and P Van Cappellen. 1990. "A New Kinetic Approach to Modeling Water-Rock Interaction: The Role of Nucleation, Precursors, and Ostwald Ripening." Geochimica et Cosmochimica Acta, Vol. 54, pp. 2657-2677.

Steefel CL and AC Lasaga. 1994. "A Coupled Model for Transport of Multiple Chemical Species and Kinetic Precipitation/Dissolution Reactions with Application to Reactive Flow in Single Phase Hydrothermal Systems.” American Journal of Science, Vol. 294, pp. 529-592.

Terrones G and LL Eyler. 1993. Computer Modeling of ORNL Storage Tank Sludge Mobilization and Mixing. PNL-8855, Pacific Northwest Laboratory, Richland, Washington.

Trent DS and LL Eyler. 1994. TEMPEST: A Computer Program for Three-Dimensional Time Dependent Computational Fluid Dynamics. PNL-8857 Vol. 1, Version T, Mod 2, Pacific Northwest National Laboratory, Richland, Washington.

Whyatt GA, RJ Serne, SV Mattigold, Y Onishi, MR Powell, JH Westik Jr, LM Liljegren, GR Golcar, KP Recknagle, PM Doctor, VG Zhirnov, and J Dixon. 1996. Potential for Criticality in Hanford Tanks Resulting from Retrieval of Tank Waste. PNNL-11304, Pacific Northwest National Laboratory, Richland, Washington. 
PNNL-11787

UC-2030

\section{Distribution}

No. of

Copies

Offsite

2 DOE Office of Scientific and Technical Information

W. L. Boyt

U.S. Army Corps of Engineers

Waterways Experimental Station

Hydraulics Laboratory

Vicksburg, MS 39180

M. H. Chandhry

Washington State University

Department of Civil and Environmental Engineering

Pullman, WA 99164

C. T. Crowe

Washington State University

Department of Mechanical Engineering

Pullman, WA 99164

R. Dyer

U.S. Environmental Protection Agency

International Office

$401 \mathrm{M}$ Street SW

Washington, D.C. 20460

M. Goldman

University of California at Davis

Laboratory for Energy-Related Health

Research

Davis, CA 95616

D. R. F. Harleman

Massachussetts Institute of Technology

Ralph M. Parsons Laboratory for Water Resources and Hydrodynamics

Cambridge, MA 02139
No. of

Copies

G. H. Jirka

Cornell University

Department of Environmental Engineering

Ithaca, NY 14853

M. Katona

Department of Civil and Environmental

Engineering

Washington State University

Pullman, WA 99164

K. Kim

Columbia University

$\mathrm{H}$. Krumb School of Mines

809 Seely W. Mudd

New York, NY 10027

R. B. Krone

University of California at Davis

Department of Civil and Environmental

Engineering

Davis, CA 95616-5294

T. Nakato

University of Iowa

Institute of Hydraulic Research

Iowa City, IA 52242

J. F. Paul

Environmental Research Laboratory

U.S. Environmental Protection Agency

Naragansett, RI 02882

P. R. Reed

U.S. Nuclear Regulatory Commission

Office of Nuclear Regulatory Research

MS-T-9B3

Washington, D.C. 20555 
No. of Copies

G. L. Schnoor

University of Iowa

Center for Global and Regional

Environmental Research

Civil/Environ. Engineering Dept.

Iowa City, IA 52242

J. E. Till, President

Radiological Assessment Corp.

Rt. 2, Box 122

Neeses, SC 29107

5 D. S. Trent

721 Lynnwood Loop

Richland, WA 99352

K. W. Yeh

U.S. Environmental Protection Agency

International Office

401 M Street SW

Washington, D.C. 20460

\section{Onsite}

1 DOE Richland Operations Office

J. J. Davis

S6-62
No of

Copies

1 MACTEC

B. B. Peters

H5-03

13 Numatec Hanford Company

P. J. Certa

H5-61

J. W. Lentsch S2-48

R. P. Marshall Jr. H5-61

C. A. Rieck (5) S2-48

J. E. Van Beek (5) S2-48

37 Pacific Northwest National Laboratory

S. Q. Bennett

K7-90

B. C. Bunker

$\mathrm{K} 8-93$

T. H. Dunning Jr.

$\mathrm{K} 1-96$

R. M. Ecker

K6-91

A. R. Felmy

K9-77

J. A. Fort

K7-15

M. D. Freshley

P8-34

R. E. Gephart

K9-76

J. P. Lafemina

P7-27

Y. Onishi (20)

K9-33

D. R. Rector

K7-15

A. Shekarriz

K7-15

W. C. Weimer

P7-27

Information Release (5) 